MONOGRÁFICO: Materiales, transporte y producción. Pósters del Workshop Internacional de Arqueología de la Construcción V, (Universidad de Oxford, 11-12 Abril 2015 / MONOGRAPH: Materials, transport and production. Posters of the 5th International Workshop on the Archaeology of Roman Construction, (University of Oxford, April 11-12, 2015)

\title{
Desde las figlinae a los edificios: el uso del barro cocido en el sur de la Baetica
}

\section{From figlinae to buildings: the opus testaceum in the southern Baetica}

\author{
Lourdes Roldán Gómez y Macarena Bustamante Álvarez \\ Universidad Autónoma de Madrid \\ e-mail: lourdes.roldan@uam.es, macarena.bustamante@uam.es
}

\begin{abstract}
RESUMEN
Se analiza la utilización del o. testaceum en contextos urbanos del sur de la Bética (Hispania), especialmente en Carteia y Baelo Claudia. Para ello se considerará como un proceso único de estudio desde la producción en las figlinae, su distribución y puesta en obra. Por ello, el análisis de estas piezas se acompañará con una valoración espacial de su territorium así como de los sigilla que aparecen sobre estos materiales, algunos de ellos, indicadores de la organización productiva en el seno del alfar.
\end{abstract}

Palabras clave: O. testaceum; Baelo Claudia; Carteia; Baetica; figlinae.

\section{ABSTRACT}

We analyzed the utilization of the o. testaceum in urban contexts of southern Andalusia (Hispania), especially in Carteia and Baelo Claudia. This shall be considered as a single study of the production process, from the figlinae, the distribution to its application in buildings. Therefore, the analysis of these pieces will be accompanied with a spatial assessment of their territorium and the sigilla that as well appear on these materials. We have to highlight that some of them are indicators of productive patterns.

Keywords: O. testaceum; Baelo Claudia; Carteia; Baetica; figlinae.

Recibido: 09-06-2016. Aceptado: 16-09-2016.

\section{Copyright}

(c) 2016 CSIC. Este es un artículo de acceso abierto distribuido bajo los términos de una licencia de uso y distribución Creative Commons Attribution (CC-by) España 3.0. 


\section{INTRODUCCIÓN}

El objetivo de este trabajo es analizar la utilización del material latericio en enclaves emblemáticos del sur de la Bética (Hispania) y, especialmente, del área del Estrecho, como Baelo Claudia o Carteia, los cuales serán valorados con el fin de conocer las soluciones técnicas utilizadas, sobre todo, en los complejos termales (Fig. 1). Bien es sabido que el uso del ladrillo en Hispania es reducido en los contextos urbanos, en los que casi en exclusividad, queda relegado a las termas. La ausencia de un figlinario docto en la fabricación de estas piezas, que ha sido utilizado como argumento principal para explicar esta escasez, no parece ser adecuado si analizamos las complejas soluciones técnicas que se adoptan en espacios específicos, como en el mundo termal. Será preciso, por tanto, buscar otras causas que expliquen este hecho en el ámbito más general de la arquitectura hispanorromana y el uso de las técnicas de construcción más adecuadas según los diferentes contextos y situaciones históricas.

En el presente artículo se realizará un análisis productivo, distributivo, morfológico y técnico, el cual se acompaña con una nueva revisión de los sigilla conocidos en estos ámbitos y que, en determinados casos, insinúan un posible intervencionismo imperial en estas obras. Todo ello se evaluará sin olvidar la presencia de un sustrato indígena y púnico único en la zona que pudo ser el impulso necesario para adoptar muy tempranamente algunas de estas innovaciones. De igual modo, no se dejará de lado, el territorium en el cual se insertan estos enclaves y en los que otros complejos termales ayudan a completar esta visión.

El ámbito espacial en el que se centra el proyecto Corpus documental, Métodos de análisis de la Arquitectura, Técnicas y Sistemas Constructivos romanos. Definición de la Cultura Arquitectónica en el Círculo del Estrecho (HAR2012-36963-C05-01), que ampara este trabajo, nos ha permitido conocer todo el proceso productivo de estos elementos, desde las propias figlinae hasta su puesta en obra.

El trabajo se articula en dos grandes capítulos, el primero dedicado al estudio de las figlinae del entorno y, un segundo, en el cual se evaluará de manera pormenorizada el uso de este material en los dos enclaves que centran nuestra atención. Este método de análisis es novedoso en Hispania ya que, hasta el momento, ambas disciplinas - la ceramología y la edilicia - parecían tener ámbitos de actuación autónomos.

\section{¿UNA RED DE FIGLINAE AL SERVICIO DE BAELO CLAUDIA Y CARTEIA?}

El espacio geográfico que vamos a analizar se caracteriza por presentar un elemento que, a su vez, lo hace casi único, como es su disposición a ambos lados de una masa de agua, el Estrecho de Gibraltar. Esto hace

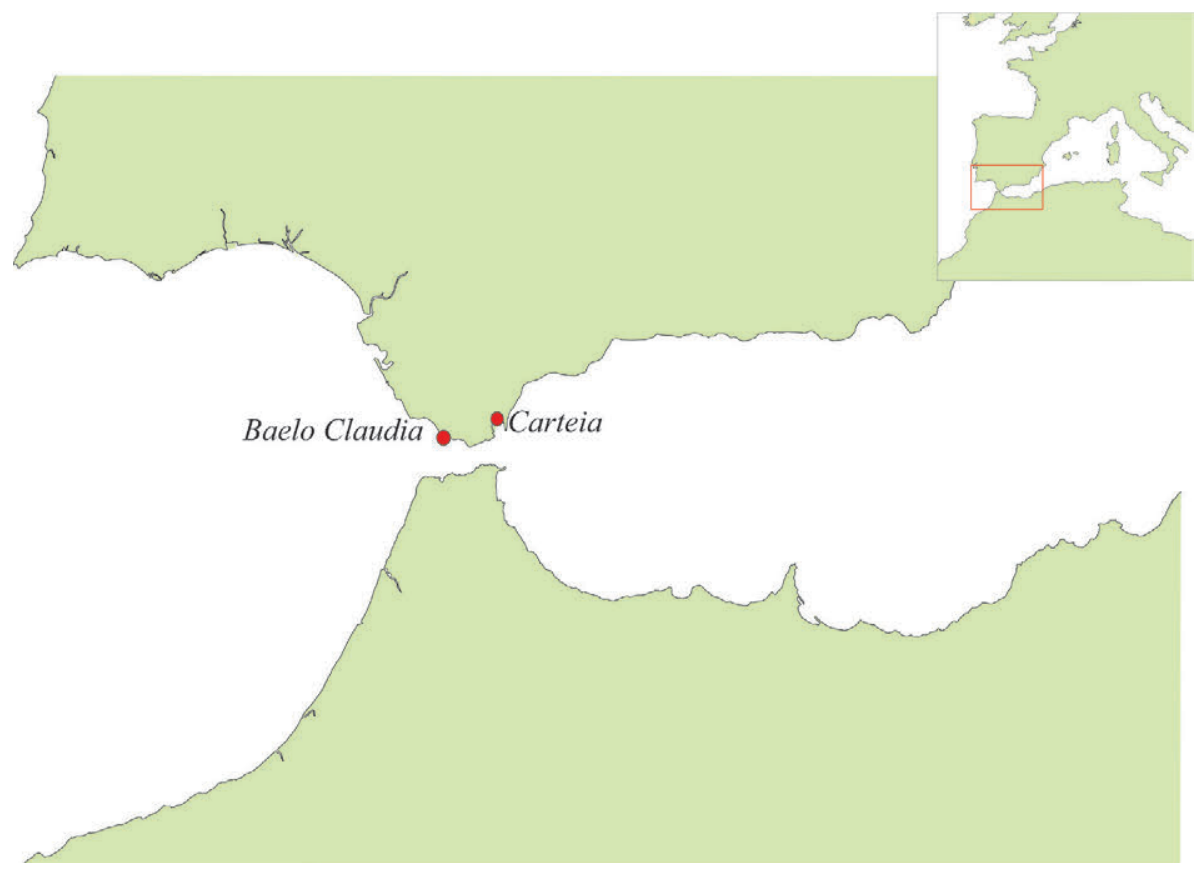

Fig. 1. Mapa con indicación de la zona de estudio. 


\begin{tabular}{|c|c|c|c|}
\hline & Alfar & Producción & Cronología \\
\hline 1 & Conservas Garavilla (Algeciras, Cádiz) & Anfórica & I a.C.-I d.C. \\
\hline 2 & El Chorruelo (Algeciras, Cádiz) & Anfórica & - \\
\hline 3 & $\begin{array}{l}\text { C/ Alexander Henderson (Algeciras, } \\
\text { Cádiz) }\end{array}$ & Comunes & Augusteo \\
\hline 4 & C/ San Quintín (Algeciras, Cádiz) & Comunes y latericio & Último cuarto del I d.C. \\
\hline 5 & El Rinconcillo (Algeciras, Cádiz) & $\begin{array}{l}\text { Comunes, ánforas (Dr. 1, 21/22-Sala I), } \\
\text { ladrillos romboidales y con sellos SCG }\end{array}$ & Primera mitad del I d.C. \\
\hline 6 & Ringo Rango (Los Barrios, Cádiz) & $\begin{array}{l}\text { Ánforas -Keay XVI, XIX, Majuelo y } \\
\text { Keay VI-, comunes, construcción }\end{array}$ & IV-V d.C. \\
\hline 7 & Venta del Carmen (Los Barrios, Cádiz) & $\begin{array}{l}\text { Ánforas (Beltrán IIa y b, Dr. 14, Dr. 7/11, } \\
\text { Haltern 70, y Dr. 18) }\end{array}$ & $\begin{array}{l}\text { últimas décadas } \\
\text { del s. I d.C. }\end{array}$ \\
\hline 8 & Pino Merendero (Los Barrios, Cádiz) & - & - \\
\hline 9 & $\begin{array}{l}\text { Moheda de Cotilla (Castellar de la } \\
\text { Frontera, Cádiz) }\end{array}$ & - & - \\
\hline 10 & $\begin{array}{l}\text { Loma del Espadañal (Castellar de la } \\
\text { Frontera, Cádiz) }\end{array}$ & - & - \\
\hline 11 & $\begin{array}{l}\text { Mesa de los Ángeles (Jimena de la } \\
\text { Frontera, Cádiz) }\end{array}$ & - & - \\
\hline 12 & $\begin{array}{l}\text { Cañada de los Almendros (Jimena de la } \\
\text { Frontera, Cádiz) }\end{array}$ & Latericios & Altoimperio \\
\hline 13 & Guadarranque (San Roque, Cádiz) & Ánforas (Dr. 7/11, Dr. 2/4 o Dr. 14) & I a.C.-I d.C. \\
\hline 14 & Factoría Campsa (San Roque, Cádiz) & Latericios, tegulae & - \\
\hline 15 & Loma de las Cañadas (San Roque, Cádiz) & $\begin{array}{l}\text { Ánforas (Dr. 7/11, Halertn 70, Beltrán II } \\
\text { a), ladrillos, ímbrices y tegulae }\end{array}$ & I a.C.-I d.C. \\
\hline 16 & Villa Victoria (San Roque, Cádiz) & $\begin{array}{l}\text { Dr. 7/11, Dr. 2/4, Haltern 70, testae, } \\
\text { tegulae, ímbrices }\end{array}$ & Augusto-VI/VII d.C.) \\
\hline 17 & C/ Aurora (San Roque, Cádiz) & - & - \\
\hline 18 & Cortijo Albalate (San Roque, Cádiz) & Ánforas, comunes, ladrillos, tegulae & - \\
\hline 19 & Arroyo Salado -Conil- & Dr. $7 / 11$ & Fines del I a.C.-primera mitad del I d.C. \\
\hline 20 & Loma del Chorrillo - Vejer de la Frontera- & Tegulae, Imbrices, ladrillos & I d.C. \\
\hline 21 & Fuente Redonda -Barbate- & Dr. 7/11 y Beltrán II a & Primera mitad del I d.C. \\
\hline 22 & Ermita de San Ambrosio & Material Constructivo & II a.C.-II d.C. \\
\hline 23 & Zahara de los Atunes -Barbate- & Anforas & Fin del I a.C.-mitad del I d.C. \\
\hline
\end{tabular}

Fig. 2. Alfares romanos localizados en el hinterland de Carteia (nn. 1-18) y Baelo Claudia (nn. 19-23) (a partir de los datos de Diaz 2011 e inéd.).

que el estudio productivo que vamos a esbozar tenga una doble vertiente geográfica, al Norte y al Sur de este emblemático espacio ${ }^{1}$.

En la actualidad, el estado aún incipiente en el que nuestra investigación se encuentra nos fuerza a plantear una serie de hipótesis que sólo en un futuro, acompañadas de estudios arqueométricos podrán verse confirmadas. Por ello, en este apartado lo que presentamos es una recopilación de figlinae en el entorno de ambos

\footnotetext{
1 Para el desarrollo de este capítulo agradecemos la ayuda aportada por el Dr. Díaz Rodríguez
}

enclaves: Baelo Claudia y Carteia que, plausiblemente, podrían haberlos surtido de estos productos (Fig. 2).

\section{La producción latericia en la orilla norte del Estrecho de Gibraltar}

La zona sur de la Bética está bien caracterizada por ser uno de los espacios que mayor producción cerámica concentró. El valle del Guadalquivir y la Bahía de Cádiz son buenos ejemplos de lo indicado por presentarse en ellos una compleja red productiva abocada, por un lado a la comercialización del aceite y, por otro, a los 


\begin{tabular}{|c|c|}
\hline \multicolumn{2}{|l|}{ Alfar de Villa Victoria } \\
\hline Tipos & Medidas \\
\hline Tegula reborde inclinado & $-\mathrm{x}-\mathrm{x}$ 1'6-2'6 cm \\
\hline Ímbrices & - \\
\hline Romboidales & - \\
\hline Segmento de círculo & - \\
\hline \multicolumn{2}{|l|}{ Alfar de Venta del Carmen } \\
\hline Tipos & Medidas \\
\hline Tegulae reborde triangular & $60-65$ x 40-45 x 1'8-2'6 cm. \\
\hline Tegulae reborde inclinado & $60-65 \times 40-45 \times 11^{\prime} 8-2 ' 6 \mathrm{~cm}$. \\
\hline Tegulae reborde cuadrado & $60-65$ x 40-45 x 1'5-2'2 cm. \\
\hline Tegulae con oculus & $60-65$ x 40-45 x 1'8-3 cm. \\
\hline Ímbrices & $33^{\prime} 6 \times 10^{\prime} 6-15 \times 1{ }^{\prime} 2-2 \mathrm{~cm}$. \\
\hline Ladrillo rectangular & $25^{\prime} 2 \times 30{ }^{\prime} 8 \times 2{ }^{\prime} 2 \mathrm{~cm}$. \\
\hline Ladrillos con orejetas & $12^{\prime} 2-12^{\prime} 5 \times 15-15^{\prime} 8 \times 5-5^{\prime} 4 \mathrm{~cm}$. \\
\hline Romboidales & $19^{\prime} 6 \times 11^{\prime} 6 \times 3^{\prime} 4 \mathrm{~cm}$. \\
\hline Circulares & $18^{\prime} 4-16$ x 5'6-7'4 cm. \\
\hline Semicirculares & $18 \times 5,5-6 \mathrm{~cm}$. \\
\hline \multicolumn{2}{|l|}{ Alfar de Ringo Rango } \\
\hline Tipos & Medidas \\
\hline Tegulae reborde triangular & $60-65 \times 40-45 \times 1$ ' $8-3$ ' $4 \mathrm{~cm}$ \\
\hline Tegulae reborde triangular y óculo central & $60-65 \times 40-45 \times 1{ }^{\prime} 8-3{ }^{\prime} 4 \mathrm{~cm}$ \\
\hline Ímbrices & - x 1'1-1'9 cm. \\
\hline Ladrillos con orejeta & $15^{\prime} 5 \times 5{ }^{\prime} 8 \times 2{ }^{\prime} 4 \mathrm{~cm}$ \\
\hline Laterculus & $9^{\prime} 5-11^{\prime} 5 \times$ x 5-5'5 x 2'5-5 cm. \\
\hline Bessalis & $17-23^{\prime} 5$ x 4'5-5'5 cm. \\
\hline Semipedalis & $-\mathrm{x} 12$ x 4'5-5 cm. \\
\hline Semilydio & $25-34 \times 19-21 \times 3-5 \mathrm{~cm}$. \\
\hline
\end{tabular}

Fig. 3. Principales tipos producidos en el alfar de la Villa Victoria, Venta del Carmen y Ringo Rango.

productos haliéuticos. El espacio que centrará nuestra atención es el ubicado en el entorno de la Bahía de Algeciras y en la denominada como Costa de la Luz que, por su proximidad geográfica a Baelo Claudia y Carteia, podrían haber estado al servicio de estos enclaves.

\section{La Bahía de Algeciras}

La bahía de Algeciras, lugar de emplazamiento de la ciudad de Carteia, cuenta con un rico sustrato margoso y cursos de aguas prestos a ser usados que potenció un rico y amplio espectro de figlinae. Aunque en la actualidad no contamos con un estudio específico sobre la producción cerámica en el Círculo del Estrecho, sí se conocen datos que permiten perfilar una primera aproximación al mapa productivo de este entorno (Díaz Rodríguez 2011 e ined..$^{2}$ ) (Fig. 3).

A priori, se observa una masiva presencia de alfares destinados a la producción de ánforas, prioritariamente, asociadas a la comercialización de productos piscícolas. En este rosario de alfares, la producción de material latericio está presente en el $47 \%$ de los complejos y, mayoritariamente, en asociación con otros productos, principalmente ánforas y cerámicas comunes. Este primer dato de corte cuantitativo nos va a avanzar una de las conclusiones fundamentales de este trabajo, como es

\footnotetext{
2 Díaz Rodríguez, J. J. (inéd.): Los alfares romanos en Hispania (s. II a.C. - VII d.C.). Sistematización de la documentación del conventus Gaditanus y análisis comparativo interprovincial, Tesis Doctoral, Universidad de Cádiz, 2014.
} 
el uso puntual y restringido de este tipo de materiales. Sin embargo, no podemos precisar si esta carencia hunde sus raíces en un déficit productivo o si esta ausencia de producción se retroalimenta por un desinterés hacia este tipo de materiales en las propias construcciones. De igual modo, el mapa cronológico-productivo nos avanza la percepción de que la producción latericia se dispara cuantitativamente y se diversifica en época bajoimperial.

A partir de un análisis exhaustivo de la historiografía vinculada a la producción cerámica, se desprende un fuerte desinterés por el estudio de este tipo de materiales. Este hecho, unido al continuo expurgo del que esta categoría cerámica es sujeto pasivo, hace de estos materiales los grandes olvidados del panorama ceramológico de la zona.

Uno de los lugares mejor conocidos en cuanto a producción cerámica en este ámbito geográfico corresponde a lo que ha sido denominado por nuestro equipo como el vicus de Villa Victoria, un barrio alfarero de Carteia (Roldán, Blánquez Bernal, Prados y Díaz 2006). En este núcleo la idea de simple figlina trasciende a un complejo habitacional y productivo en la zona extra moenia de la Colonia, activo entre época augustea y los ss. VI/VII d. C. No obstante, los procesos deposicionales propios de un alfar, con un vertido de piezas fragmentarias, hacen que no sea posible valorar mediciones completas.

Junto con este barrio, claramente dependiente de Carteia, también aparecen otros enclaves de menor entidad pero, de igual modo, bien posicionados en el entorno y que, puntualmente, también podrían haber servido estos productos a la ciudad.

En primer lugar, estaría la figlina de la Venta del Carmen, activa entre el cambio de era y la época flavia. Ésta presentaba un horno de planta cuadrangular y una producción de ánforas selladas con la indicación CNPFCR, interpretada como el trianomina CNP unido a F(iglina) $C(a) R$ (teiana) (Lagóstena y Bernal 2004: 52). El interés del complejo se asienta en ser uno de los mejor estudiados en lo que se refiere al material constructivo (Torrecilla, Sánchez, Gómez y Ochoa 2002).

En segundo lugar, se encontraría la figlina de la villa de Puente Grande, Ringo Rango (Los Barrios) con una amplia producción alfarera en época tardorromana, fin del IV - inicios del V d. C. Presenta dos hornos y, de nuevo, una producción diversificada con ánforas y material latericio (Lagóstena y Bernal 2004: 52).

Paralelamente, ya fuera del ámbito espacial de la Bahía de Algeciras, concretamente en la figlina de
Burguillos — Sevilla - se ha localizado recientemente un ejemplar de tegula con sello alusivo a Petrucidius. El hecho de localizarse este sello en ámbito productivo ha sido primordial para lanzar la propuesta de que esta $f$ glina habría sido el centro productor de estas piezas que, por otra parte, han sido ampliamente documentadas en Carteia (Bernal, García Vargas, Lavado, Díaz, Luaces, y Gethsemaní 2014: fig. 1a). De hecho, a pesar de esta hipótesis de trabajo que ubica espacialmente este complejo en el Conventus Hispalense, la principal concentración de este tipo de sigilla, como luego veremos, se focaliza en Carteia (para más datos Del Hoyo 2006). Este dato nos parece de interés ya que la distancia entre ambos enclaves sería mayor de $200 \mathrm{~km}$ lo que nos hablaría de un comercio muy organizado y, sobre todo, masivo para que fuera rentable a efectos de comercialización.

\section{La Costa de la Luz}

El ámbito costero comprendido entre Tarifa y Barbate presenta un mapa productor más pobre quizás eclipsado por los dos focos productivos entre los que queda constreñido. En primer lugar, la Bahía de Cádiz y, en segundo lugar, la de Algeciras comentada en el apartado previo. En este espacio geográfico, casi el $30 \%$ de los pocos alfares documentados presentan producción de material latericio y, como previamente vimos, en asociación a otras categorías cerámicas.

A diferencia de lo que ocurre en el ámbito de la bahía de Algeciras, en este caso contamos con el problema de que se trata de estudios realizados años atrás sin que se haya llevado a cabo ningún tipo de análisis de estas piezas. Dicho handicap, sin duda, coarta nuestra capacidad de análisis del ámbito productivo.

\section{La Mauritana Tingitana y el abastecimiento interprovincial de material latericio}

En nuestro espacio geográfico, el caso de Baelo Claudia constituye un ejemplo paradigmático a la hora de analizar el abastecimiento del material latericio utilizado, debido a que la llegada de piezas de ultramar parece haber dado respuesta a este fenómeno. A ello debemos unirle el suministro por parte de figlinae que se sitúan en lugares más cercanos a la colonia carteiense que al enclave baelonense, como sería el alfar del Rinconcillo (Étienne y Mayet 1994) cuyos sellos, tanto anfóricos como latericios se han documentado en Baelo Claudia.

La citada hipótesis de importaciones norteafricanas hunde raíces en la aparición de un abultado elenco de 
marcas sobre los ladrillos de las termas. El interés de las mismas se eleva al ser sellos imperiales que tienen paralelos directos, tanto formales como en la composición de su soporte, en el norte de la Mauritania Tingitana (Étienne y Mayet 1971). Dicho interés, además, se acrecienta por la localización de los mismos no sólo en ámbitos de consumo sino también en figlinae, caso de Gandori (Étienne y Mayet 1971), cuyo radio de distribución parece también afectar al sur de la Mauritania Tingitana (Camporeale 2015) o en el entorno de Tamuda, recientemente confirmado por análisis arqueométricos (Bernal, Bustamante, Díaz y Raissouni 2012). A priori, se podría suponer una llegada de piezas puntuales fruto quizás de la necesaria praxis de lastrar el barco, un problema solventado de manera variada por los romanos como nos indica Plinio (Nat. Hist. 16, 201-2, 36, 60-70). Sin embargo, la homogénea composición de pastas de todo el lote utilizado en las termas y el elevado número de sellos -tanto en obra como en piezas depositadas en los almacenes del Conjunto Arqueológico- nos hablan de un conjunto premeditado y encargado al amparo de un proyecto organizado (Roldán y Bustamante 2015: 142).

Del taller de Gandori, que es el que centra nuestra atención, no se han localizado estructuras de combustión, sin embargo, los abundantes desechos localizados de antiguo, y ya referidos por el propio Thouvenot (1954) y por Ponsich (1970), han sido los elementos con los que se contaba para establecer esta hipótesis. Ponsich, concretamente hacía un elenco de tipos producidos en este taller entre los que destacaban los testae cuadrangulares, en cuarto de círculo, con escotaduras, o las tegulae. El interés del complejo radica, sobre todo, en la aparición de sellos de clara titularidad imperial HADRI AVG, ANTO AVG y EX FIGVL CAES con una producción amplia en el tiempo, que pervive hasta bien entrado el IV d. C. (Mueden 2008: 422), o hasta el V d. C. (Villaverde 2001: 299). En este caso la cercanía a un campamento militar, lo mismo que ocurría en Tamuda, sería un dato incontestable para la aparición de este tipo de sellos.

A tenor de lo hasta ahora conocido, el comercio del material latericio fue una realidad en época antigua. Ello habría estado amparado, quizás, en una compleja red comercial articulada por determinadas figlinae o artesanos - como ocurre con L.Herennius Optatus para el levante peninsular (para más datos Rodá 2015) - que, necesariamente, implicaba precios muy competitivos. $\mathrm{O}$, posiblemente, la carestía de filones plásticos en determinados núcleos poblacionales, hizo de una práctica poco fructífera - como es la producción y venta a escala de ladrillos - un recurso económico bastante rentable.

En el Círculo del Estrecho se observa un accidente físico que no actúa como freno para el comercio de estas piezas sino que, más bien, implica una organización muy específica e intensa entre los talleres y el consumidor. Este fenómeno de traslación de piezas con una posible "barrera" también se aprecia entre Italia y Dalmacia con un comercio a través del Adriático (Wilkes 1979: 70). El paralelo en este último caso es aún más cercano si tenemos en cuenta, además de la existencia de un elemento intermedio - en este caso el Adriático-, la alusión directa al nombre del emperador reinante. Si bien se trata ahora de un elenco más amplio que se desarrolla entre los reinados de Tiberio y Vespasiano y que se asocia nominalmente con el dueño de taller, Pansiana así como a otros artesanos, Solonas y Cinniana (Wilkes 1979: 67-68).

Similar fenómeno se aprecia también en otro espacio geográfico. Se trata del círculo espacial existente entre el sur del Reino Unido y la Bretaña Francesa donde, de nuevo, una masa de agua, el canal de la Mancha actúa como elemento de separación salvable para el comercio de este tipo de piezas (Peacock 1977).

\section{EL USO DEL LATERICIO EN LA ORILLA NORTE DEL CÍRCULO DEL ESTRECHO}

El uso del latericio en la zona sur de la Bética podemos decir que es muy restringido. El tradicionalismo constructivo "extremadamente conservador" de la arquitectura antigua (Gros 1983; Mar Medina 2008) explicaría, en cierto modo, el uso mantenido de materiales locales de más fácil acceso, o de técnicas de construcción bien conocidas y el rechazo a innovaciones que requerían una compleja infraestructura de producción -madera para alimentar los hornos, mano de obra abundante y poco especializada, etc. (Roldán 2008: 768). Sin embargo, en un momento más avanzado se observa una serie de innovaciones puntuales que engrandecerán el saber constructivo de los romanos (Lancaster 2016).

Sin embargo, cuando se analizan las soluciones técnicas que fueron utilizadas en los edificios termales nos planteamos una serie de dudas. En primer lugar, parece evidenciarse que el conocimiento técnico de este tipo de materiales era amplio y, en segundo lugar, que el 
uso de este opus - seguramente por cuestiones económicas - no fue rentable. En este apartado comentaremos de manera muy somera el uso de este material en los enclaves de Baelo Claudia (Fig. 4a) y Carteia (Fig. 4b).

\section{Baelo Claudia}

Lo mismo que ocurre en Carteia, Baelo Claudia cuenta con un sustrato geológico óptimo para el desarrollo de una arquitectura pétrea. Los afloramientos de caliza fosilífera, de Almarchal y del Algibe (Ménanteau, Vanney y Zazo 1983) aportan recursos suficientes como para darle la espalda a la producción latericia, sobre todo, teniendo en cuenta que se trataba de un producto que no estaba presente en la tradición alfarera de la zona.

En Baelo Claudia se observa la ausencia casi total de este tipo de materiales en toda la ciudad, hasta el punto de que, a partir de un primer análisis constructivo realizado hace ya algunos años podemos exclusivamente hablar de un uso focalizado en las termas centrales y en la necrópolis.

\section{Las termas del foro}

Las termas de Baelo Claudia fueron intervenidas en 1969 gracias a las excavaciones desarrolladas por la Casa de Velázquez. A día de hoy podemos decir que no ha habido un trabajo amplio que haya analizado el edificio de manera íntegra sino que han surgido diversos trabajos en el seno del equipo francés que han permitido valorar tanto la campaña de 1970 (Bourgeois y Del Amo 1970) como los sigilla localizados (Étienne y Mayet 1994).

A partir de un análisis constructivo de las termas podemos asegurar que el uso del ladrillo estuvo concentrado, principalmente, en las pilae/suspensurae así como en la cubierta. Puede observarse, por tanto, que se
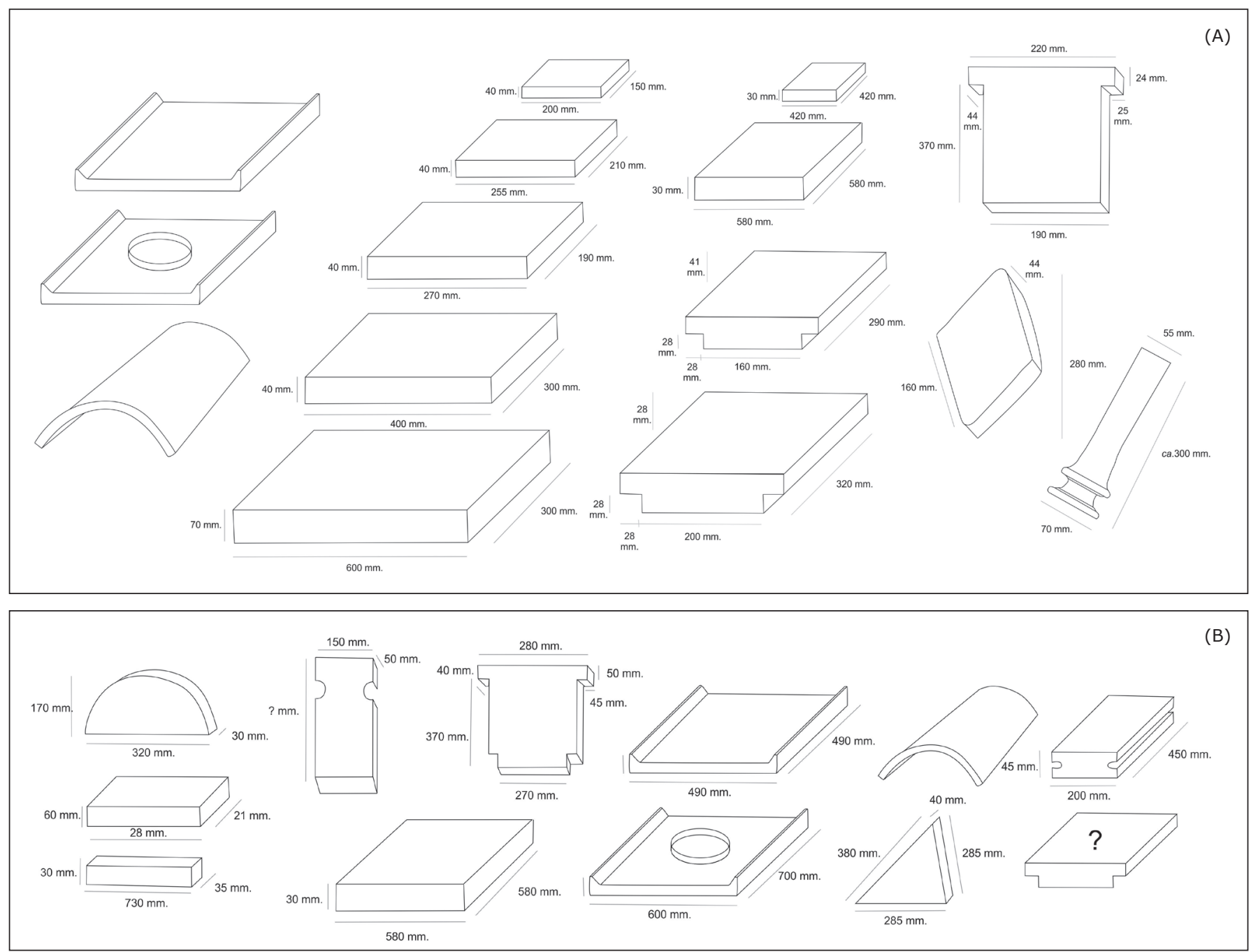

Fig. 4. Principales tipos de ladrillos localizados en Baelo Claudia (A) y Carteia (B). 
trata de un uso muy específico y asociado a problemas técnicos difícilmente salvables con el uso de la piedra. Si tenemos en cuenta que tanto la producción de ladrillos como el uso de opus testaceum no está muy atestiguado en la zona sería muy plausible pensar en una importación de estos productos allende el Estrecho de Gibraltar (Fig. 5).

El uso de estas piezas en ámbito termal ha sido ampliamente estudiado (Fernández Ochoa, Morillo y Zarzalejos 1999; Roldán 1995). Esta práctica está amparada por una constante alusión de las fuentes clásicas a las bondades del uso del latericio en ambientes húmedos ( $\mathrm{p}$. ej. Vitrubio V, 10, 2 o Plinio Nat. Hist. 35. 159). Uno de los trabajos más extensos sobre esta temática, elaborado por Bouet (1999: 13), evalúa el uso y las ventajas de estos materiales en ambientes termales muy cálidos. En primer lugar, las elevadas temperaturas a las que se llega en estos ambientes pueden generar una constante dilatación que, el material latericio, podría soportar. En segundo lugar, su consistencia porosa, ayuda a mantener durante más tiempo la constante térmica. Por ambos motivos su uso está bien atestiguado en el ámbito calefactado.

Para abordar este estudio de los ladrillo baelonenses nos hemos centrado, en primer lugar, en el análisis de las piezas que, aún in situ, se documentan en las termas. En segundo lugar, se ha procedido a la autopsia de los materiales localizados durante el proceso de excavación del edificio que aparecían en los niveles de derrumbe exhumados.

Espacialmente, las piezas se localizan únicamente en los tepidaria, en el caldarium, así como en la fuente del caldarium, en tres ubicaciones concretas:

- pilae y arquillos de la suspensura

- carretes de anclajes de las dobles paredes

- bóvedas y sistema de calefacción en altura

Con respecto al primer tepidarium, podemos decir que es la sala mejor conservada y la que menor proceso de restauración ha sufrido. En ella aparecen diez líneas de arquillos divididos en treinta y seis arcos con dirección

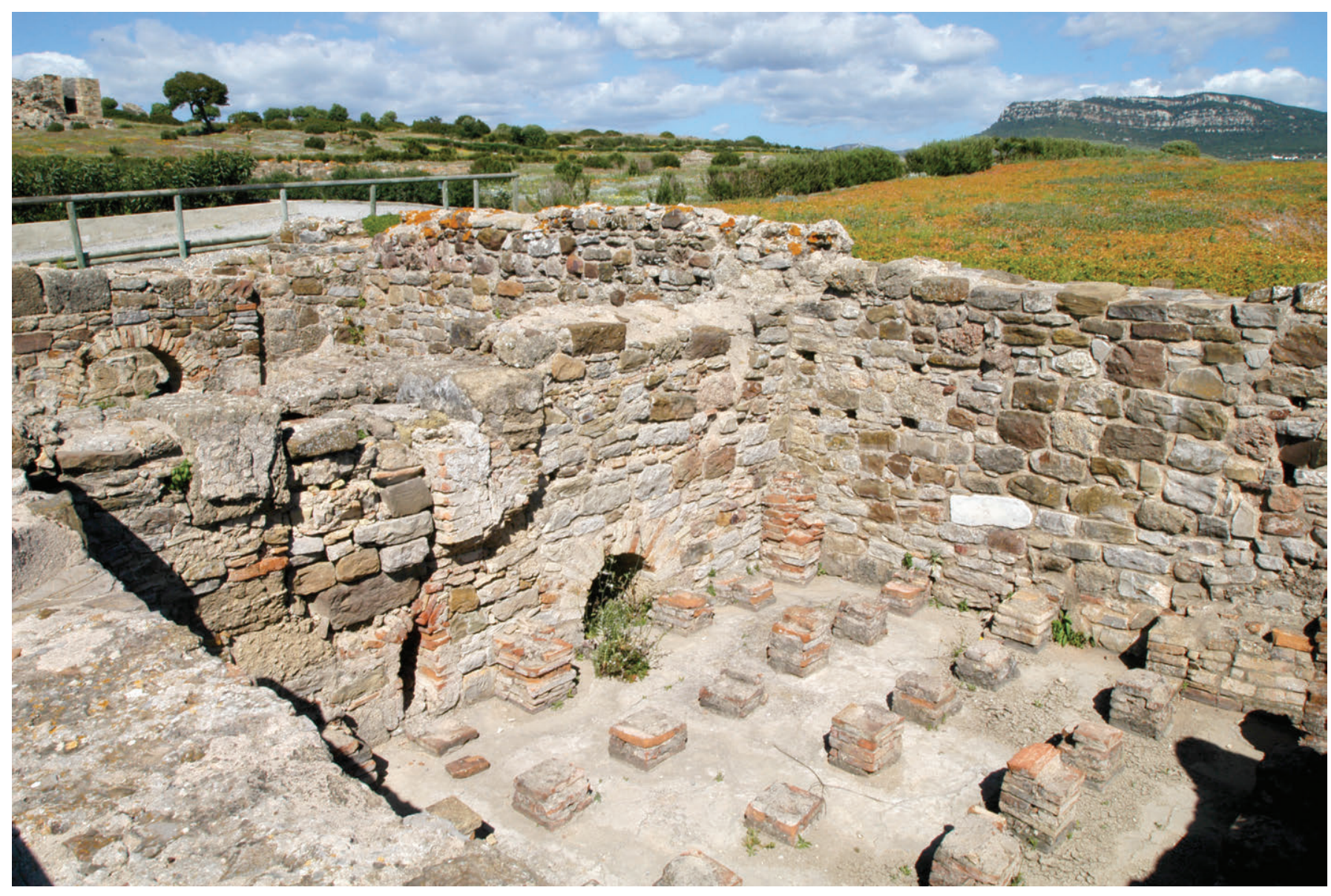

Fig. 5. Vista parcial del complejo termal de Baelo Claudia. 
N-S. Dichos arcos están unidos por medio de pechinas también rellenas con fragmentos de material latericio recortados. Una estimación numérica de las piezas nos permite afirmar que la suspensura de la primera sala podría albergar hasta 1960 ladrillos de los cuales más del 95\% aparecen sellados. De manera individualizada, las pilae se forman a partir del uso de ladrillos rectangulares $(20 / 21 \times 15 / 16 \times 3 / 4 \mathrm{~cm})$ en número de dos que se elevan hasta configurar seis hiladas. En ocasiones estos dos ladrillos se sustituyen por una única pieza $(29 / 31$ × 22 × $6 \mathrm{~cm})$ lo que genera una mayor consistencia de estos soportes. Sobre los arquillos de las pilae apoyaría un estrato de grandes ladrillos $(60 \times 30 \times 5 \mathrm{~cm})$ sobre el que se dispuso una gruesa capa de signinum que actuaría como pavimentación de la sala.

Para generar la cámara por la que elevar el aire desde la zona inferior se procedió a la construcción de una sobrepared de placas de cerámica que permitiera circular el aire cálido hacia la zona superior y calefactar las bóvedas. Para ello se utilizaron carretes de cerámica con vástago de aprox. $30 \mathrm{~cm}$ de longitud que permitían, con una espiga metálica, anclar las placas. Una lectura de paramentos nos permite determinar un uso ordenado en cuanto a hiladas horizontales, sin embargo, lo que no queda claro es la distancia vertical equidistante entre ellas que permita obtener un módulo concreto de placas.

La unión entre cada una de las salas calefactadas se producía a partir de un pequeño arco de medio punto con ladrillos con leve cuña, que presentan un módulo $(29 \mathrm{x}$ $20 \times 4^{\prime} 5 \mathrm{~cm}$ ) totalmente distinto a los que se observan en las salas propiamente dichas. La diferencia también se acentúa por la utilización de una arcilla totalmente distinta, de color más amarillento.

La segunda sala templada, de nuevo, viene a repetir el esquema compositivo de la anterior pero con una ordenación y dirección totalmente distinta de los arquillos de la suspensura que, en este caso, se disponen E-W. El módulo utilizado en esta ocasión es el de 27/29 x 19/20 $\mathrm{x} 4 / 5 \mathrm{~cm}$ que viene a corresponder a una dimensión de casi el doble de los ladrillos dispuestos en las pilae. De nuevo se repite el uso de clavijas para anclar las placas y generar una cámara de circulación del aire cálido.

El tercer espacio en el que se observa la aparición de ladrillos es el caldarium y su piscina adyacente, donde se vuelve a repetir el esquema de la sala anterior. En ambos casos el uso de los ladrillos sellados se reduce en número, hecho que creemos puede corresponder a una refacción a posteriori de la terma. El único espacio donde se mantiene la cuantificación en el uso de ladrillos sellados es la piscina lateral del caldarium donde el buen estado de conservación nos permite valorar la colocación de los arquillos y de una atarjea "a la capuchina" in situ.

Para concluir con el espacio inferior del complejo termal contamos con la aparición de un módulo concreto de piezas en el praefurnium. Concretamente se documenta un banco corrido a ambos lados de la puerta realizados con ladrillos de una medida, hasta el momento, no localizada en el edificio (41 x 20 x $4 \mathrm{~cm}$ ). Esta diferencia también se aprecia en la propia composición del material latericio con una arcilla de coloración más clara y menos depurada.

De la cubierta pocos son los datos que podemos valorar in situ debido al fuerte deterioro que presenta la estructura. El único indicio perceptible es la aparición de unos tubos cuadrados horadados en la piedra, a modo de tiro, junto con el sistema de cámara calefactada generada por el uso de bovinas.

Así pues, para poder conocer el sistema de bóveda del complejo debemos recurrir a las piezas que se ubican en los depósitos del conjunto arqueológico de Baelo Claudia. Allí hemos podido realizar una amplia autopsia de las piezas y, por consiguiente, plantear una posible reconstrucción del sistema de cubrición.

Concretamente se utilizaron para ello ladrillos rectangulares con orejetas $(37 \times 29 \times 4 \mathrm{~cm})$ que se alternarían con placas de lengüeta lateral que se apoyarían sobre las orejetas. Ambos tipos presentan sección ligeramente curva para ajustarse a la bóveda. Del análisis se desprende el uso de dos tipos de placas unas de mayor tamaño $(32 \times 20 \times 28)$ y otras más pequeñas $(29 \times 16 \times$ 41). Este doble módulo permitiría ir ajustando la obra al espacio restante. El interés de estas piezas, es que, casi en su totalidad, aparecen selladas con el mismo sello y posicionados en el mismo punto, a excepción de algunos ejemplares que presentan un sellado diferente y que, $a$ posteriori, valoraremos.

Cronológicamente, el uso de bóvedas calefactadas en el Imperio es muy amplio, desde los primeros complejos termales datados en el primer tercio del I d. C., hasta avanzado el siglo III d. C., momento en el que se atestigua un declive de las instalaciones termales. Para la narbonense, este tipo de bóvedas está bien atestiguado entre el fines del I d. C. con su inicial presencia en Limoge y finales del IV d. C. en Montoulieu (Bouet 1999: 93), lo que nos indica un saber formal eficaz y muy amplio en el tiempo. Otros autores restringen su uso entre el final del II d. C. y los inicios del IV d. C. 
(Fincker 1986: 146). En relación a su aparición en otros puntos del Imperio sigue siendo significativa su ausencia en Italia o su, por el contrario, masiva presencia en la Mauritania Tingitana.

Retornando, de nuevo, al ejemplo de Baelo Claudia, un análisis amplio de las termas nos permite afirmar la existencia de dos fábricas distintas de su material constructivo. En primer lugar, se percibe un tipo más duro y consistente de coloración rojiza muy oscura con desgrasantes calcáreos que asociamos a las partes que presentan una mayor dificultad técnica. En segundo lugar, los otros ejemplares presentan una pasta amarillenta cuarteada y se focalizan únicamente en los vanos de comunicación entre una habitación y otra. La otra gran diferencia es que la fábrica más oscura e imperante presenta, casi en su totalidad, ladrillos sellados por los sigilla asociados a las fábricas imperiales.

Llegados a este punto debemos plantearnos cuál sería el motivo de la llegada de estas dos fábricas. Creemos que una opción plausible sería la producción y compra de este tipo de materiales más complejos técnicamente en talleres especializados y que, concretamente, parecen estar asociados a una producción militarizada como demuestran los ejemplares de Tamuda y Gandori y posicionada a la otra orilla del Estrecho. Se produciría así la compra de un lote completo destinado, en exclusividad, a la construcción de las pilae y de la bóveda. Únicamente, en algunas partes del complejo, como en el praefurnium o el poyete corrido de la entrada se utilizaron los otros materiales a los que nos hemos referido.

Para finalizar se ha localizado un ejemplar romboidal de amplias dimensiones, concretamente de $280 \mathrm{~mm}$ de largo por $160 \mathrm{~mm}$ del cual, sin embargo, no se ha localizado in situ ningún indicio que pudiera apuntar a su uso en esta instalación. A pesar de ello, creemos que este ejemplar procede de las termas y su uso, estaría, indudablemente, unido a las solerías. El hecho de que las salas cálidas y templadas estén pavimentadas con opus signinum creemos que apuntaría directamente a las salas frías y de recreo como las más óptimas para presentar este tipo de pavimentación.

En relación a la fabricación de los ladrillos utilizados en este edificio, uno de los puntos que más nos interesa resaltar es la presencia de algunas señales que nos inducen a valorar el proceso productivo seguido para su fabricación. Generalmente se observa el uso de moldes de madera que dejaron impresas algunas marcas en los productos manufacturados. En el caso de los ladrillos rectangulares, dichas marcas se hacen patentes por la aparición de una línea incisa y tenuemente plegada que hablaría de moldes de madera, cuyo desmolde habría forzado la impronta de estas hendiduras. Habría un molde específico para el desarrollo de las piezas más grandes, las cuales una vez generadas serían despiezadas en más pequeñas. Este despiece se llevaría cabo a partir de lamas de madera o metálicas que favorecieran un corte limpio. El análisis de las piezas cocidas nos permite ver el sistema de ensamblado de las láminas de madera del molde a partir de espigas, datos que hasta el momento no habíamos podido definir (Fig. 6).

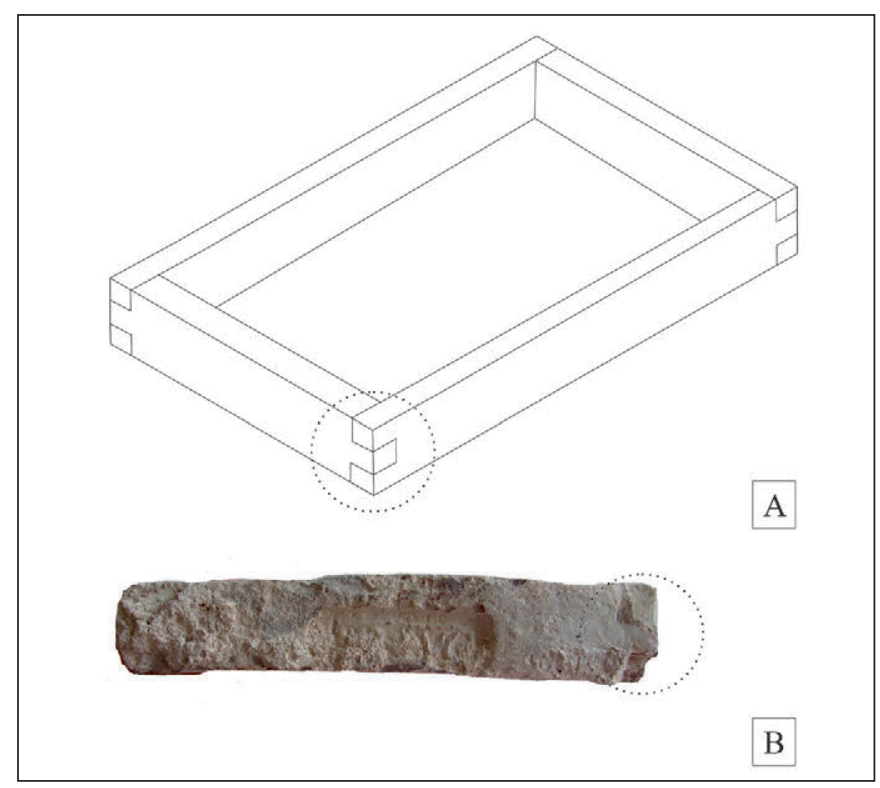

Fig. 6. Detalle de las marcas de molde localizadas sobre los ladrillos y posible reconstrucción del molde.

Uno de los ejemplares más clarificadores serían los ladrillos de orejetas que presentan marcas en las esquinas de una caja ensamblada a partir de un sistema de espiga intercalado. El uso de moldes de madera ha sido ya apuntado para la producción de material latericio, con ejemplos de piezas de este tipo que se localizan en Egipto, concretamente en un depósito del Kahun o ya en época más moderna en muchos puntos de la geografía mediterránea (p. ej. Shepherd 2007: fig. 3).

\section{La necrópolis de Baelo Claudia}

En el plano funerario se observa una total reticencia al uso del ladrillo en la necrópolis de Baelo Claudia en los primeros momentos de vida. Ya desde las intervenciones llevadas a cabo por P. Paris y otros (1926: 59-71) se pone de relieve la ausencia de este tipo de materiales 
en los monumentos más relevantes arquitectónicamente hablando. Este hecho sorprende al propio P. Paris pues es un recurso técnico usado para el mismo tipo de tumbas - concretamente las cilíndricas - en otros espacios de la Bética como en Cañada Honda (Gandul) o Carmo (Carmona). En esta primera monografía también se aportan algunas fotografias que nos permiten valorar la proliferación de tumbas con cubierta a la capuchina así como con cubierta plana de tegulae (Archivo General de Andalucía, fotografía 273 y 274). Este tipo de estructuras, a falta de un análisis estratigráfico actual, se le ha supuesto un carácter transicional entre las últimas incineraciones y las primeras inhumaciones y, en su amplia mayoría, están asociadas a tumbas infantiles, al menos, en el área funeraria Este (Paris, Bonsor, Laumonier, Ricard, y Mergelina 1926: 87; VV.AA. 2009: nn. 70-7133). Pocos años antes, Furgus (1907: 155-159) ponía sobre la mesa la aparición de más de treinta tumbas con cubierta a dos aguas en la necrópolis Oeste, datadas a mitad del II d. C.

Junto con las tumbas de inhumación, la presencia de las tegulae en los enterramientos con ritos de incineración también está atestiguada en Baelo, sobre todo, como parapeto de protección de las cenizas de los difuntos en los busta (Sillières 1997: 197).

\section{Cubriciones}

Evidentemente uno de los usos menos constatados, debido al estado de conservación de las estructuras, serían las cubriciones. Una de las únicas alusiones al tema vendría de la mano del equipo que intervino el templo de Isis en las inmediaciones del foro. El estudio proponía un complejo sistema de cubrición a un agua de uno de los pórticos que circundaban el complejo isiáco. Se aludía a la existencia de cornisas con huecos que posibilitaba el encastre de un esqueleto de madera que, a su vez, habría permitido colocar unos tablones que generaban una superficie plana para, a partir de ella, posicionar las tegulae así como los ímbrices (Fincker 2008: fig. 44).

\section{Carteia: las termas y la necrópolis de Villa Victoria}

Uno de los motivos por los que se ha esgrimido la falta del barro cocido en la zona, además de las reticencias amparadas por el inmovilismo tradicional, es por un

VV.AA. 2009: Jorge Bonsor y la recuperación de Baelo Claudia (19171921). Consejería de Cultura de la Junta de Andalucía, Sevilla. contexto geológico muy propicio como cantera. Concretamente, calizas fosilíferas y margosas, areniscas o la denominada "losa" de Tarifa, hacen del entorno un espacio idóneo para abordar el progreso urbanístico que la Colonia Latina Libertinorum Carteia afronta a fines de la República (Roldán 1999: 182).

Lo mismo que ocurre en otros puntos peninsulares a inicios del I a. C. se percibe la inserción del barro cocido en la arquitectura carteiense a partir del uso de tegulae e imbrices destinados a las cubriciones. En este contexto cronológico, el acompañamiento de estas piezas con referencias epigráficas, caso de los sigilla M. PETRVCIDIVS M.F. / LE.PRO. M. LICI, apuntan a un hito cronológico y un episodio histórico focalizado en la Bética a fines del I a. C. (una revisión actualizada en Del Hoyo 2006).

Sin lugar a dudas, el único espacio donde sí se tiene constancia de un proyecto de obra con uso específico del ladrillo son las termas. Sin embargo, un análisis arqueo-arquitectónico de la obra nos ayuda a valorar este uso en un segundo momento de vida de dicho complejo entre fines del I e inicios del II d. C. (Roldán 1992; 1995: 809 ss.)

En primer lugar, encontramos su utilización en el muro de separación entre el caldarium y el tepidarium. Este muro presenta $84 \mathrm{~cm}$ de grosor y está realizado con ladrillos rectangulares de módulo regular $(29 / 30$ x 22 x $5 / 6 \mathrm{~cm}$ ) con una compleja disposición alterna posicionados con una compleja red machi-hembrada. En segundo lugar, y como vimos en Baelo Claudia, se percibe su aparición en el hypocaustum. Este espacio, destinado a soportar la suspensura, presenta una técnica edilicia típicamente itálica y oriental por la ausencia de arquillos sobre los que descansar el pavimento (Nielsen 1990: 14). Para ello se usan ladrillos semicirculares (de $32 \mathrm{x}$ $17 \mathrm{~cm}$ ) que se colocaron alternando su eje para, de este modo, conseguir una mayor consistencia. Sobre la pilae se dispuso directamente una hilada de ladrillos $(59 / 60 \mathrm{x}$ $29 \times 4 \mathrm{~cm}$ ) sobre la cual se superpuso una capa de argamasa muy tosca, una nueva hilada de ladrillos, en este caso reutilizados y, por último, dos capas más de opus signinum de las que la superior es más depurada. En algunos puntos del suelo, concretamente en las zonas de acceso de una sala a otra, se colocaron amplias losas bipedales a modo de umbral (Fig. 7).

En tercer lugar, el uso del material latericio también está atestiguado en el specus realizado para la canalización del ciclo del agua dentro del complejo termal, así como formando parte de los conductos de evacuación de las aguas de las termas. 


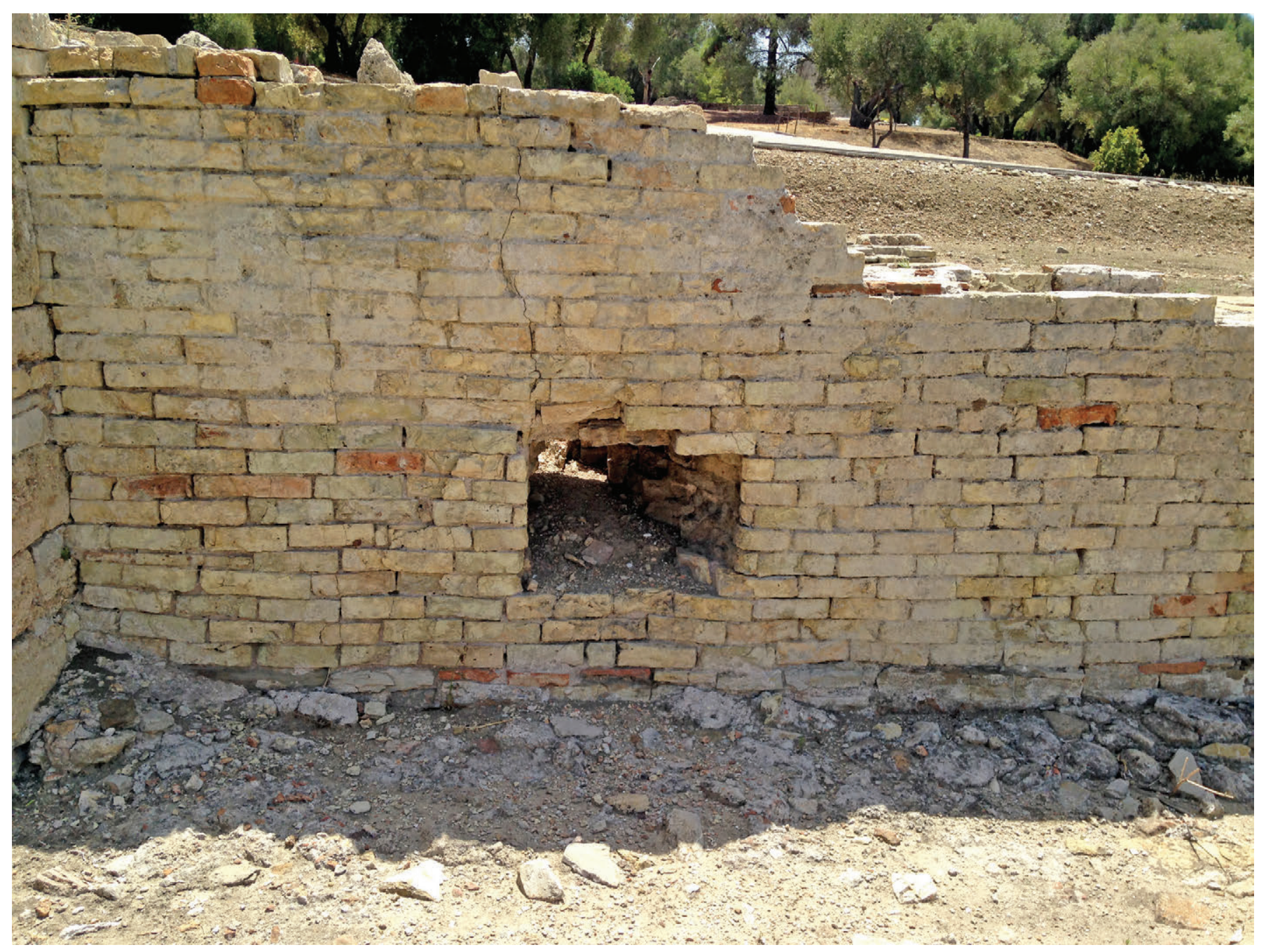

Fig. 7. Detalle del uso del opus testaceum en Carteia.

Para finalizar, se utilizaron elementos latericios en la construcción de la pared y de las bóvedas calefactadas. Aunque las intervenciones son muy antiguas, los materiales depositados en el museo de San Roque nos permiten llevar a cabo una serie de apreciaciones que ayudan a proponer una posible reconstrucción del sistema. Se trata de ladrillos con muesca superior (de $28 \times 22 \times 5 / 6 \mathrm{~cm}$ con muesca de $4 \mathrm{~cm}$ en cada lateral y de $18 \times 15 \times 5^{\prime} 3 \mathrm{~cm}$ ), así como placas con lengüetas que nos permiten reconstruir técnicamente una bóveda calefactada. La cámara de aire estaría generada por medio de un ladrillo colocado de manera saliente que permitiría generar este espacio. Así, este sistema viene a reproducir el desarrollado en Baelo aunque la gran diferencia es la ausencia del sistema de clavijas/carretes que, en este caso, se suple por el uso de ladrillos colocados horizontalmente.

De todo el elenco de ladrillos antes referido y que, en su casi totalidad, proceden de las termas, es necesario destacar dos piezas. En primer lugar, un ladrillo cuneatus cuya principal función es facilitar la construcción de arcos. La ausencia de espacios arcados actualmente conocidos y, sobre todo, la definición de un hypocaustum, formado por pilares rectos y no por pequeñas arcadas - como sí pasa con Baelo Claudia-, permiten plantear la más que plausible posibilidad de que existiera otro espacio calefactado, actualmente no conocido. En segundo lugar, también parece de interés la aparición de un ladrillo triangular tradicionalmente usado para ser embutido en muros con núcleo de opus caementicium. Esta técnica, de clara raíz itálica — donde se encuentran estos ladrillos con bastante asiduidad - fue escasamente desarrollada en Hispania donde se optó mayoritariamente por ladrillos rectangulares (Roldán 1999: 186; 2008: 752 ss.). En el caso de Carteia, estos ejemplares han sido documentados formando parte de las cistas de las tumbas tardoantiguas localizadas en el foro y posiblemente de cronología previa. 
A pesar de lo indicado el uso del ladrillo en Carteia no es exclusivo de las termas ya que en otros puntos de la ciudad también se observa. Sin embargo, como ya hemos apostillado previamente, este uso se hace de manera muy esporádica y, en gran medida, como medio de gestionar residuos arquitectónicos previos por medio del reciclado que está bien representado en la ciudad, tanto en el área forense, como en el teatro y en las propias termas. En primer lugar, en la parte baja del foro se produjo un uso de material latericio, fuera del proyecto de obra, en el muro frontal de las tabernae A, B así como en una canalización de la taberna C (Roldán 1992: 5356). De igual manera, en la plataforma superior del foro se utilizaron estos materiales para realizar una compartimentación tardía en el interior del templo republicano. También se perciben las posibles reutilizaciones para configurar las tumbas tardías presentes tanto en el foro como en las termas, aunque en este último edificio fueron retiradas (Bernal 2011: 150).

Otros interesantes ejemplos del uso de latericio en las necrópolis aparecen documentados en fotografías de las excavaciones realizadas por Martínez Santa-Olalla en los años 50. Aunque la ubicación de estas necrópolis es imprecisa debido a la ausencia de documentación escrita sobre las excavaciones, las fotografías de las mismas no dejan lugar a dudas del tipo de material empleado en la configuración de algunos de los enterramientos. Se trata en concreto de dos necrópolis; la denominada de la Huerta del Gallo y fechada tradicionalmente en época tardía y la del entorno de la torre del Rocadillo, junto a la muralla que comprende un amplio espectro cronológico desde la época altoimperial hasta el tardo imperio (Roldán y Blánquez 2011: 141-144; Roldán y Blánquez 2012: 108-110).

En relación al uso de la arcilla sin cocer en las construcciones de Carteia, el empleo del adobe y del tapial está bien atestiguado en el precedente periodo púnico de la ciudad en alzados y elevaciones de muros con zócalos de piedra que, con el tiempo, han ido desapareciendo tal y como el Proyecto Carteia ha puesto de manifiesto en las últimas anualidades. Es un tema aún por valorar debidamente, en el que venimos trabajando, hasta qué punto la tradición constructiva de época púnica influyó en las posteriores construcciones romanas. En este sentido ha quedado abiertamente demostrado que los cambios transicionales que se produjeron en Carteia con la llegada del mundo romano fueron muy graduales y extendidos en el tiempo. Los aspectos constructivos no quedarían fuera de esta tendencia que ha quedado bien atestiguada en el aprovechamiento de estructuras púnicas anteriores en el posterior asentamiento romano (Arévalo, Blánquez, y Roldán e. p.; Blánquez, Roldán, y Jiménez e. p.), así como también en la cultura material (Roldán, Blánquez, Bernal, Prados y Díaz 2006). No se trata aquí de ahondar sobre este fenómeno del que, únicamente, queremos llamar la atención.

\section{LA EPIGRAFÍA LATERICIA}

Una de las paradojas que presenta el uso del ladrillo en nuestra zona de estudio es que, a pesar de su escasa presencia, el índice de material sellado es elevadísimo. Concretamente, uno de los edificios que hemos analizado, las termas de Baelo Claudia, presenta sellos en casi un $80 \%$ de las piezas localizadas in situ. Este elevado número plantea un fenómeno alejado de lo que suele ser común en Hispania y que, por consiguiente, pone sobre la mesa una práctica difícilmente explicable con la hipótesis que en la actualidad se baraja sobre el uso de los sigilla.

\section{Elenco de sigilla documentados en Baelo Claudia}

Podemos decir que esta ciudad, junto con Itálica, son los enclaves que mayor número de sigilla presentan. Concretamente en Baelo Claudia se han podido documentar más de trescientos veinte sellos de los cuales el $96 \%$ proceden de las termas. Esta repetición en su ubicación también se reitera en su morfología si tenemos en cuenta que de todo este número de sigilla, únicamente se han podido determinar siete punzones distintos, de los que tres se localizan en los sellos de las termas (Fig. 8).

El fenómeno del sellado del material latericio en época romana ha generado mucha controversia ya que tanto su posicionamiento, como su cronología, significación y, sobre todo, praxis son continuo objeto de análisis sin que exista aparente consenso en la comunidad científica.

Quizás uno de los puntos que más interesa para nuestro análisis es el de su función. En relación con ello, tanto la contabilidad en los centros de producción (Böcking 1978: 113), como la exención de tasas, la expresión de una locatio-conductio (Steinby 1982: 227-237) o la prohibición de su uso fuera de determinados contextos 


\begin{tabular}{|c|c|c|c|c|}
\hline Sellos & Transcrpción & Ubicación & Soporte & Bibliografía \\
\hline & Carteia & Post-desposicional & Tegula & Del Hoyo 2006, 49/1 \\
\hline & CNT(arquini) & Post-desposicional & Tegula & Del Hoyo 2006, 55 \\
\hline $\begin{array}{l}\text { HERCVID } \\
\text { HERCVIS }\end{array}$ & Hercules / Hercules & Termas y El Rocadillo & Tegula & $\begin{array}{l}\text { Catálogo del Museo de S. } \\
\text { Roque, n. } 41\end{array}$ \\
\hline LMAESSINA & L Maessina & Post-desposicional & Tegula & Del Hoyo 2006, 51 \\
\hline$M$ & (.) $M L()$. & El Rocadillo & Ladrillo & Del Hoyo 2006, 52 \\
\hline & $P \cdot P$ & Post-desposicional & Tegula & Del Hoyo 2006, 54/3 \\
\hline $\begin{array}{l}\text { M.PETRVCIDIVS MF } \\
\text { LEC.PRO PR.M.LICI }\end{array}$ & $\begin{array}{l}M(\text { arcus) Petrucidius } \\
M(\text { arcus) F(ili) / Leg(atus) } \\
\text { Pro Pr(aetrore) M(arcus) } \\
\text { Li(cini) }\end{array}$ & $\begin{array}{l}\text { El Rocadillo y la Torre } \\
\text { de Carteia }\end{array}$ & Tegula & $\begin{array}{l}\text { Presedo y otros 1982, fig. } \\
\text { 102, n. 1, p. } 175 \text { y lám. IX }\end{array}$ \\
\hline
\end{tabular}

Fig. 8. Cuadro sinóptico de los tipos de sellos localizados en Baelo Claudia.

—como los militares- (Spitzlberger 1968: 82 o Peacock 1982: 137), son algunas de las interpretaciones aportadas. A ello debemos añadir toda una serie de sigilla más complejos, sobre todo gestados en Roma, cuya extensa nómina epigráfica ha hecho que hayan sido interpretados como el contrato entre el dueño de la cantera de arcilla y aquel que sustentaba la propiedad de la fábrica propiamente dicha. Recientemente, además de estas interpretaciones que podemos determinar como de carácter profano, se ha planteado, a propósito de los sellos de la Regio Octavia Aemilia, una sacralidad intrínseca en el acto del sellado, interpretación que, aunque muy sugestiva, necesita ser contrastada (Pellicioni 2010).

Si nos centramos en los sellos de Baelo Claudia, uno de los primeros ejemplares localizados corresponde a un sigillum hallado en el sondeo 36 de la excavación desarrollada por la Casa de Velázquez en 1966 y espacialmente ubicado en la zona sur de la ciudad. En dicho sello se puede leer en letras incusas el epígrafe [.] VCR $\cdot S \cdot C \cdot G$ (Domergue 1973: 56, n. 2098), cuyo desarrollopodríaserel siguiente: $[L] v \mathrm{cr}($ eti) $\cdot(S$ (ocietas) . $C$ (etarii).G(aditanorum). Este dato nos parece muy resaltable ya que en él se repite el esquema de sellado de algunas ánforas de salazones localizadas en Baelo, tradicionalmente asociada a una societas organizada a tal efecto y cuyo centro productor se localizaría en el alfar del Rinconcillo en Algeciras (para más datos Étienne y Mayet 1994: 131-138). En relación con ello y también sobre tegula [S(ocietas) C(etarii)] G(aditanorum) se localizó otro ejemplar en Baelo que volvía a incidir en esta formulación epigráfica (Rico 1999: fig. 4e). Asimismo, aunque con un formato ligeramente distinto pero con el mismo agente de actuación $M$. Lucretius, se localizó otro ejemplar en la intervención de 1966, en el sondeo 26 ubicado la zona suroeste de la ciudad. En esta ocasión los caracteres también son incusos y se puede leer $[O] p(u s) \cdot M \cdot L u c r(e t i)$ (Domergue 1973: 75, n. 764).

Además de estos ejemplares se documentó un sello sobre ladrillo en el que se lee con letras en relieve Tarq (Rouillard, Remesal, y Sillières 1975: 533, pl. XIX, n. 2) que podría desarrollarse como Tarquinii. No existe ningún otro ejemplar de similares características en Baelo Claudia aunque, sin embargo sí contamos con una alusión directa a dicha familia en Carteia, gracias al sello CNT desarrollado recientemente como Gnei Tarquinii asociado directamente al legado Petrucidius (Del Hoyo 2006: 55).

En el cómputo general de los sellos de Baelo Claudia el grupo que aparece más reiteradamente, con diferencia, es el que alude a la familia imperial. Concretamente se han localizado dos fórmulas distintas: Imp(eratoris) Aug(usti) y Imp(eratoris) Aug(usti) G(e)r(manici). Ambas marcas 
aparecen de manera aleatoria tanto en pequeños ladrillos rectangulares, en ladrillos de orejeta, así como en las placas destinadas a formar las bóvedas calefactadas. De ellas, un $99 \%$ de los casos aparecen posicionadas en los cantos de las piezas, en los lados cortos y, casi siempre, muy centrados mientras que, en el caso de las placas de encaje vienen a coincidir con la parte más gruesa de la sección.

Únicamente, en tres ocasiones hemos podido atestiguar la presencia de las marcas en la cara inferior o superior de las placas que nos permite considerar una función distinta a la que estamos acostumbrados a definir. Concretamente consideramos que este cambio en el posicionamiento podría corresponder a una posible función administrativa o de contabilidad, como sería la de señalizar lotes cerrados de piezas con un número clausus concreto. La hipótesis de que los sigilla sean marcas de contabilidad dentro de las figlinae ya fue planteada por Böcking (1978: 113) lo que parece confirmarse con el ejemplo que apuntamos en Baelo Claudia. Esta posición del sello sobre uno de los lados planos, documentada en nuestro ejemplo, evitaría tener que inclinarse para ver el sello y, en consecuencia, permitiría conocer el volumen de las piezas allí apiladas desde una posición erguida del contable.

El que se haga alusión a la titulatura imperial apoya la idea de que fueron manufacturadas en talleres de esta propiedad, de lo que existe un amplio elenco de ejemplos recogidos en Roma (Steinby 1993: 140), así como también se distribuyen por toda la cuenca mediterránea $y$, especialmente, en la Mauritana Tingitana (Thouvenot 1954 o Ponsich 1970: 268).

La primera marca imperial citada correspondería a Imp(eratoris) Aug(usti) en cartela rectangular con esquinas redondeadas y enmarcada en la zona superior e inferior por dos líneas excisas al igual que la totalidad de las letras, con la única excepción de la "p" que aparece incusa al quedar envuelta por las otras letras. También aparece una variante en la que todos los caracteres son en relieve perdiéndose la "p" incusa. Este hecho aludiría a la existencia de dos matrices pero con similares características en cuanto a dimensiones. Estas piezas ya fueron estudiadas para la Tingitana por Ponsich (1970: 380) quien las databa en el siglo III d. C. como fecha más temprana y cuya datación también se aplicó a las termas de Baelo Claudia (Étienne y Mayet 1971: 68). No obstante, el estudio más reciente de estas piezas viene a considerarlas de la época de Teodosio (Villaverde 2001: 299) a partir de la recopilación de datos previos.
A pesar de lo anteriormente indicado, con fecha reciente se ha aportado una nueva datación para las termas de Baelo retrotrayendo la inicial cronología a la primera mitad del II d. C. (Sillières 1995: 162). Es preciso considerar, sin embargo, como su propio excavador afirmaba, que "el hundimiento de los suelos ha alterado grandemente la estratigrafía (...) aunque para comprobar la verdad de esta hipótesis habría que hacer un sondeo", es decir, que la datación de este espacio no parece estar bien definida ya que se basa, principalmente, en paralelos estructurales (Lenoir 1991: 158-159).

Retornando al análisis del epígrafe, es innegable que alude a la figura del emperador por lo que el problema estriba en intentar asignarlo directamente a un emperador. Si bien no es posible en la actualidad atribuirlo con certeza a ninguna figura concreta, creemos que tendríamos que asociarlo a momentos previos a los Antoninos, momento de auge de estos elementos (Chic 2001: 509). A ello habría que añadirle un dato arqueoarquitectónico como sería la supuesta caída de la bóveda primigenia de las termas que podemos deducir del uso de bloques de ladrillos de orejetas de bóvedas en posición secundaria. La solidez de estas cubriciones está bien demostrada (Lancaster 2016), por lo que el colapso debió estar motivado por un hito traumático como el acaecido en la zona a mitad del I d. C. y cuyos efectos más sobresalientes se han localizado en la muralla (Sillières 1995: 57). La existencia de un segundo complejo termal - las denominadas termas marítimas - de menor entidad y más alejado del núcleo neurálgico de la ciudad, con niveles de construcción en época tardo-neroniana y con una fuerte reforma en pleno II d. C. (Bernal, Arévalo, Muño, Expósito, Díaz, Lagóstena, Vargas, Lara, Moreno, Sáez y Bustamante 2013: 131), nos induce a pensar que previamente ya estaría construido el complejo termal forense, de ahí la cronología altoimperial que le presuponemos.

El segundo tipo localizado correspondería a la marca Imp(eratoris) Aug(usti)G(e)r(manici). Esta interpretación de lectura fue dada acertadamente por Arévalo y Bernal (2007a y 2007b: 77-79) y asociada posiblemente a Domiciano. El problema se acentúa, de nuevo, al intentar asociar esta titulatura con un emperador. Si seguimos con la idea que planteamos, de otorgar a las termas y, consecuentemente, a estas piezas una cronología altoimperial, podríamos asociar este tipo de sello al emperador Claudio. Dicho emperador heredó la titulatura de "Germanico" que ostentaba su padre como se observa en algunas leyendas 
monetales. Este dato cronológico no debería sorprendernos dado que fue en época de Claudio cuando la ciudad, además de recibir el título de Claudia, iniciaría un fuerte ascenso económico acompañado por una efervescencia constructiva (Sillières 1997: 56-58). Nuestra propuesta es centrar la construcción de este complejo termal en torno a la mitad del I d. C. coincidiendo con el momento del evento sísmico, e inmediato apogeo de la ciudad amparado con una fuerte actividad constructiva desarrollada por parte del emperador Claudio. Recientemente un estudio funcional del edificio viene también a plantear esta fecha (Gómez Araujo 2013). Para esta nueva hipótesis, esta autora habla de un mismo proceso constructivo para las tiendas delanteras y el edificio termal propiamente dicho (Gómez Araujo 2013: 175). Si se confirmara esta hipótesis, el material cerámico localizado en las tiendas sí hablaba de una cronología focalizada en el siglo I d. C. (Mayet 1971: 409) pudiéndose así extrapolar esta datación a todo el complejo.

Como conclusión se documentan tres grupos de sellos según la epigrafía. En primer lugar, un conjunto que hace referencia a M. Lucretius y a la Societas Cetarii Gaditanorum y cuyo principal interés radica en que dicho sello repite el formulario registrado en las ánforas que han sido ligadas al comercio de este preciado bien. De hecho, un análisis morfológico de los sellos nos permite afirmar que las matrices fueron las mismas tanto en las ánforas como en los materiales constructivos. Esto aludiría a una producción polivalente tanto de ánforas como de otro tipo de materiales, en este caso de tegulae, asociados a las conservas pesqueras.

Dicha explicación a priori nos podría resultar extraña debido a la intensa actividad haliéutica de Baelo Claudia que precisaría un abastecimiento continuo de ánforas y, por consiguiente, la manufactura de material latericio podría quedar diluida. Sin embargo, un análisis minucioso de los procesos pesqueros nos permite considerarlo como un fenómeno estacional y, por consiguiente, la cadena de producción cerámica también podría verse alterada y desviada a otros menesteres, en este caso la producción latericia. Este fenómeno no sólo atañe a la producción de salazones sino que también parece documentarse en el arco noreste peninsular donde se encuentra el ejemplo del sello MARI, el cual aparece tanto en tegulae como sobre ánforas Dr. 2-4 (Berni 2010: n. 161). Otro ejemplo sería el sello P VSVL VEIE[.] que se localiza en Llafranc sobre tegulae, además de sobre ejemplares de ánforas Pascual 1 (Rico
1993: 56, fig. 1b), o el sello PHARALI en el Algarve que de nuevo se vuelve a repetir sobre ánforas (Veiga 1974-1977: fig. 1).

El segundo sello aludiría a un productor independiente del que únicamente tenemos constancia de su nomen Tarquini pero que sí podemos relacionar directamente con otro ejemplar localizado en Carteia y asociado al legado Petrucidius.

El tercer grupo vendría a corresponder a una serie de sellos con alusión a la titulatura imperial tradicionalmente valorados como bajoimperiales y que, con la lectura que ahora realizamos, proponemos asociarlo a la primera mitad del I d. C. Ambos sellos podrían aludir a algún emperador de la dinastía Julio-Claudia, posiblemente Claudio coincidente con el ascenso urbanístico que vive la ciudad en ese momento. En tal caso, el uso de material latericio sellado con este epígrafe sería una manera fácil, rápida y llamativa de dejar patente quién produjo la financiación de dicho edificio. El hecho de que no se hallan localizado otros edificios o muros en los que se emplee el ladrillo como material constructivo no nos permite hacer valoraciones comparativas al respecto, sin embargo, la similitud técnica que se percibe en la construcción de este espacio con respecto al macellum, quizás podría apuntar a que se trata de una obra pública.

\section{Los sellos documentados en Carteia}

El caso de Carteia dista mucho de lo que hemos podido ver en Baelo Claudia. En primer lugar, hay un descenso bastante significativo del número de ladrillos que se ha podido documentar en las construcciones de esta ciudad, hecho que propicia también el limitado número de sellos documentados. Y, en segundo lugar, no se ha localizado en la actualidad ningún ejemplar sellado in situ que nos permita hablar de un posible intervencionismo público en sus construcciones (Fig. 9).

Para el periodo tardorepublicano resulta especialmente interesante el ejemplo de Carteia (Roldán 1992; Bendala y Roldán 1997; Roldán, Bendala, Blánquez y Martínez 2006), donde el primer material constructivo cocido que se ha documentado se asocia a la utilización de tejas con la marca M. Petrucidius, natural del Piseno y legado pro praetore de Augusto. En esta ocasión la marca aparece enmarcada en una cartela rectangular, con doble fila escrita en letras capitales incusas en las que se puede leer M(arcus) Petrucidius M(arcus) F(ili) / Leg(atus) Pro Pr(aetrore) M(arcus) Li(cini), así como 
[M(arcus) Petrucidi]us M(arci) f(ilius) / [leg(atus) pro p]r(aetore) sin asociación directa con otro personaje. Podemos decir que es uno de los sigilla con mayor campo epigráfico hallado en la Península Ibérica. Estas piezas han generado una fuerte literatura sobre su interpretación desde el siglo pasado y que recientemente ha sido revisada en el seno de nuestro equipo de investigación (Del Hoyo 2006). En un inicio Hübner interpretó la figura de Petrucidius como legado de un procónsul $M$. Licinio, sin embargo, a posteriori Desssau habló de $M$. Licinio así como de otro nombre que aparecía, Alexander como alfareros al servicio de Petrucidius legado de Cn Pompeyo (Broughton 1951).

Esta producción ha sido relacionada con la actividad de fortificación realizada en torno al año $45 \mathrm{a}$. C. en ciudades béticas del bando pompeyano con motivo de la guerra civil (Presedo, Muñíz, Santero, y Chaves 1982: 279-282). Si bien, en Carteia podría haber estado vinculada a una importante renovación arquitectónica constatada arqueológicamente en el sector del llamado foro de la ciudad (Bendala y Roldán 1997). El examen de las pastas de estas producciones ha permitido apuntar su fabricación en talleres costeros ubicados seguramente en la propia Carteia, a pesar de que el único ejemplar dentro de un contexto productor lo debemos ubicar en Sevilla (Bernal, García Vargas, Lavado, Díaz, Luaces y Gethsemaní 2014). Estas piezas no sólo se han localizado en Carteia y su ager sino que aparecen diseminados por la cuenca del Guadalquivir como en la Albaina (Ceán 1832: 255), Hasta Regia (CIL II, 4967, 1b), Italica (Presedo y Caballos 1988: 509) o en Siarum (González 1989: 520-521). Quizás esto aportaría datos de una renovación arquitectónica no focalizada en exclusividad en Carteia sino en general en otros territorios fruto de una actividad edilicia impulsada por la propia Roma (González 1989: 522).

Como hemos dicho, una de las marcas del legado se asocia a otro sello con caracteres incusos y enmarcado en una cartela rectangular en la que se lee CNT y que recientemente ha sido desarrollado como $C N(e o)$ T(arquini) (Del Hoyo 2006: 55). Aparece en un lugar cercano a la otra marca de Petrucidius pero sin solaparse en la misma pieza.

Como ya vimos previamente, un sello con este nomen ya fue localizado en Baelo Claudia hecho que podría poner sobre la mesa una posible vinculación productiva y de abastecimiento entre ambos yacimientos. $\mathrm{Al}$ igual que la marca comentada, existe otra tegula con

\begin{tabular}{|c|c|c|c|c|}
\hline Sellos & Transcripción & Ubicación & Soporte & Bibliografía \\
\hline & $\begin{array}{l}\text { Imp(eratoris) Aug(usti) } \\
G(e) r(\text { manici) }\end{array}$ & $\begin{array}{l}\text { Baños y factorías de } \\
\text { salazones }\end{array}$ & $\begin{array}{l}\text { Ladrillo y ladrillo con } \\
\text { escotadura }\end{array}$ & $\begin{array}{l}\text { Arévalo y Bernal 2007, } \\
\text { fig. } 14\end{array}$ \\
\hline & $\operatorname{Imp}($ eratoris) Aug(usti) & Termas & Ladrillo & $\begin{array}{l}\text { Étienne y Mayet 1971, } \\
\text { tab. III }\end{array}$ \\
\hline & Imp(eratoris) Aug(usti) & Termas & Ladrillo & $\begin{array}{l}\text { Étienne y Mayet } 1971 \text {, } \\
\text { fig. } 2\end{array}$ \\
\hline & $\begin{array}{l}{[L] v \mathrm{vcr}(\text { eti }) \cdot(S(\text { ocietas }) \cdot} \\
C(\text { etarii }) \cdot G(\text { aditanorum })\end{array}$ & Post-deposicional & Tegula & $\begin{array}{l}\text { Domergue, } 1973,56, \mathrm{n} . \\
2098\end{array}$ \\
\hline & $\begin{array}{l}{[S(\text { ocietas }) C(\text { etarii) }]} \\
\text { G(aditanorum) }\end{array}$ & Post-deposicional & Tegula & Ricco 1999, fig. 4e \\
\hline & {$[O] p(u s) \cdot M \cdot \operatorname{Lucr}($ eti $)$} & Post-deposicional & Tegula & Domergue, 1973,75, n. 764 \\
\hline & Tarq & Sur de la Basílica & Ladrillo & $\begin{array}{l}\text { Rouillard, Remesal y } \\
\text { Sillières } 1975,533, \text { pl. } \\
\text { XIX, n. } 2\end{array}$ \\
\hline
\end{tabular}

Fig. 9. Cuadro sinóptico de los tipos de sellos localizados en Carteia. 
un doble sellado, reiterándose el sello de Petrucidius junto con las dos letras P.P (Del Hoyo 2006: 51-52 y $54 / 3$ ) que quizás podría ser $P$ (ecunia) $P($ ublica). Estas dobles marcas evidencian, por un lado, una asociación $\mathrm{y} /$ locatio conductivo puntual $\mathrm{y}$, por otro, la convivencia de un sello público con otro de carácter privado. Según Del Hoyo (2006: 40-41) M. Licinius, Cn Tarquinius a lo que habría que añadirle Alexander podrían haber sido los tegularii al servicio de Petrucidius.

El siguiente ejemplar correspondería a los sellos Herculis / Herculis en el que las letras y la cartela aparecen incusas. El formato del sello nos parece digno de resaltar al presentarse en dos cartelas individualizadas y posicionadas una encima de la otra. También la propia alusión a la divinidad titular del sitio lo hace único entre todos los sellos recopilados en Hispania hasta la fecha.

Otros ejemplares localizados serían el de L Maessina y (.)ML(.) (Del Hoyo 2006: 51-52). El primero aparece con caracteres incusos, mientras que el segundo se enmarca en una cartela con los caracteres en relieve. De estos sellos pocos datos más podemos aportar debido al grado de fragmentación que presentan.

Quizás el sello más conocido de este enclave correspondería al de CARTEIA. Concretamente se trata de un sello con cartela poco definida y con los caracteres en letra capital incusa. Mayoritariamente aparecen sobre tegulae quedando el sellado de ladrillos para otros cuños. Lamentablemente todos los ejemplares proceden de contextos deposicionales, hecho que limita mucho la información cronológica de los mismos.

Dicho sello hace claramente alusión al nombre de la Colonia y, por consiguiente, hablaría de un intervencionismo municipal en la producción y del mecenazgo de la obra. A pesar de ello, no podemos precisar el grado y categoría de participación del ente público. Quizás tengamos que pensar en una locatio conductio a un figulus independiente -hecho atestiguado para los sellos de Roma (Steinby 1982: 227-237) así como para otras categorías cerámicas, como lucernas o ánforas-, o bien en figlinae municipales. El caso de Carteia no es el único, ya que contamos con ejemplos similares en Conimbriga con el sello R(es) P(ublica) C(onimbrigensis) (Étienne, Fabre y Lévèque 1976: 297, pl. XXIII), en Mérida con el epígrafe C(olonia) I(ulia) A(ugusta) E(merita), en Celti con el de Pop(ulus) Celti (CIL II 4967, n. 17), en Tomar con el ejemplar R(es) P(ublica) S(eiliensis) (Da Silva y Ferreira 2002: 260, Est. I) o en Villavieja de Muñó con el ejemplar Mun(icipium) Arci (Liz Callejo 1974: lám. 2, n. 4).

\section{CONCLUSIONES}

Tras el análisis realizado en el presente artículo podemos decir, a modo de conclusiones, que las ciudades analizadas de la Betica - Baelo Claudia y Carteia - son expresivas del empleo del material latericio de manera específica y experta, introduciendo soluciones técnicas complejas propias de un buen conocedor del uso de este material. Por esta razón, creemos que los ladrillos se utilizaron intencionadamente de manera puntual, con abrumadora mayoría en los edificios termales de ambas ciudades, no solo para el acondicionamiento de las zonas calefactadas - hypocaustum y suspensura-, sino también en cubriciones y canalizaciones. No dudamos de que en esta elección pesó de manera importante el hecho de que para la construcción del resto de edificios monumentales resultaba más práctico $\mathrm{y}$, seguramente más económico, el empleo de otro tipo de materiales y técnicas, más tradicionales, conocidas y accesibles (Fig. 10).

No podemos discernir, en el estado actual de nuestros conocimientos, hasta qué punto las anteriores tradiciones constructivas podrían haber influido en esta elección; es probable que sí lo hicieran, pero es algo que aún no podemos valorar con datos concretos.

Creemos haber demostrado a través de estas líneas el interés de este enfoque en la investigación que aúna la producción del material latericio con su puesta en obra. Se trata de una línea de análisis aun poco valorada, aunque ya iniciada por nosotros hace algunos años, pero en la que todavía queda mucho por hacer. De hecho, los datos que aquí presentamos demuestran que son aún muy escasos los alfares en los que se ha estudiado la producción latericia en la misma medida que se ha hecho con otras producciones cerámicas.

Por otro lado, tampoco es ajena a ello la ausencia de análisis de pastas y estudios arqueométricos que permitan determinar la procedencia de los materiales lo que resulta imprescindible, especialmente, ante la ausencia o escasez de sellos existentes en lo hasta ahora conocido. De ahí el interés de hacer una recopilación de todos ellos en el conjunto de Hispania en lo que estamos trabajando dentro del proyecto en que se encuadra este trabajo.

Un hecho cierto es que la abundancia de sustratos arenosos en el entorno de los dos núcleos urbanos objeto de este estudio propició la concentración de figlinae - especialmente en la bahía de Algeciras y no tanto en la costa de la Luz - lo que también potenció la producción de ladrillos. No obstante, dicha producción se haría siempre de forma minoritaria lo que pudo haber sido 


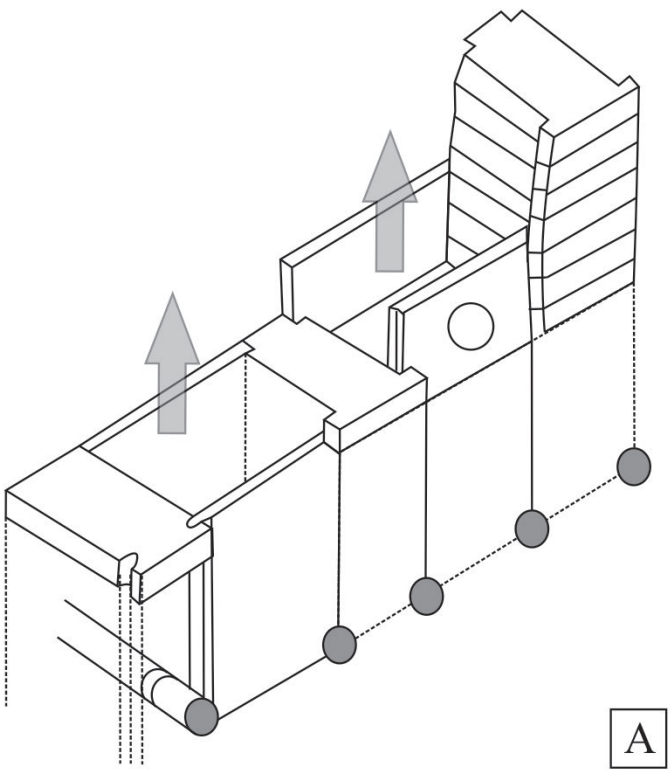

$0 \quad 1 \mathrm{~m}$.

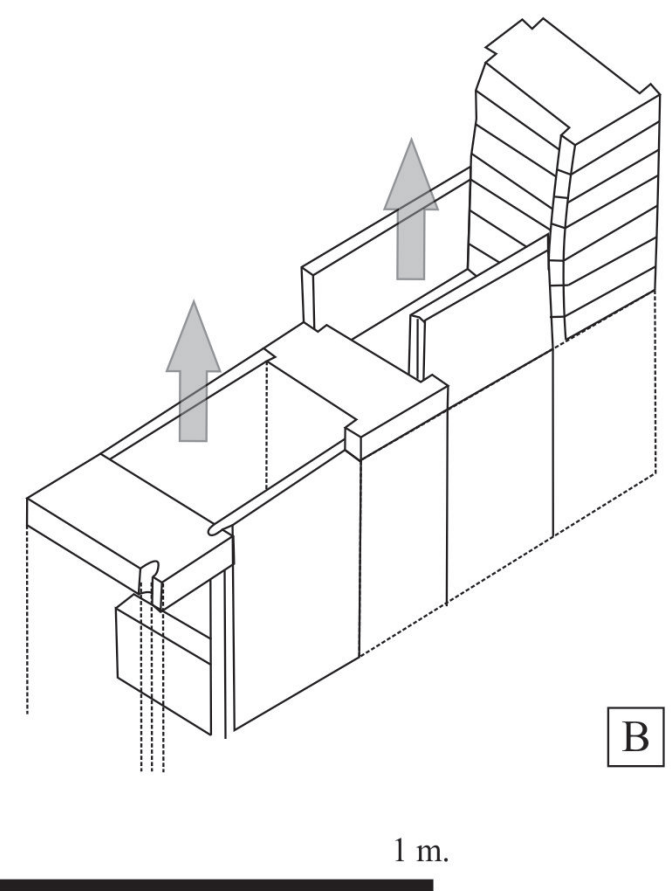

B

Fig. 10. Hipótesis de reconstrucción de las bóvedas de los complejos termales de Baelo Claudia (A) y Carteia (B).

provocado, no por completo pero sí al menos en parte, por la estacionalidad de las industrias a las que dichas figlinae abastecían de contenedores. En cualquier caso, no deja de ser llamativo el hecho de que la producción latericia fue mucho más abundante en el bajo imperio, a lo que habrá que buscar una explicación quizás en relación con la propia estructura económica y productiva de este periodo.

El análisis de los sigilla, nos ha permitido constatar que no siempre los núcleos urbanos fueron abastecidos por los alfares más cercanos como lo demuestra, por ejemplo, el caso de los ladrillos con la marca Petrucidius que quizás habrían sido producidos en la figlina de Burguillos, en Sevilla, a más de $200 \mathrm{~km}$ de la ciudad de Carteia. Otro ejemplo es el de los ladrillos traídos expresamente de Mauritania Tingitana para las termas de Baelo para lo que el supuesto escollo del Estrecho de Gibraltar, que había que atravesar, no actuó como barrera sino como elemento de comunicación de ambos núcleos, por otro lado, bastante cercanos entre sí en línea recta. Estos ejemplos demuestran, sin lugar a dudas, la existencia de un comercio activo de material latericio, de medio alcance.

Al analizar el uso de estos ladrillos conservados in situ hemos podido constatar — algo ya señalado por nosotros con anterioridad - que se trata de material muy diversificado que responde a necesidades y funciones muy concretas dentro del acondicionamiento de las zonas calientes de las termas. Como aspecto complementario de gran interés podemos decir que los materiales latericios, al margen de que se encuentren o no in situ, nos permiten en muchas ocasiones adivinar su función. Es el caso de las bóvedas, obviamente las estructuras que con menor frecuencia se documentan in situ. La existencia de ladrillos con orejetas, o de lengüeta, o las placas con lengüeta, como las que se documentan en los ejemplos presentados, no dejan lugar a dudas de su empleo en dobles paredes o en bóvedas calefactadas.

Otro aspecto a resaltar de este estudio es que las características físicas de los ladrillos hallados en un mismo contexto - como en los termales - pueden ser un elemento esencial para indicarnos momentos de construcción distintos, o bien remodelaciones en fases posteriores del primer proyecto del edificio. Asimismo, el análisis directo y minucioso de los ladrillos conservados permite extraer algunas conclusiones acerca del proceso productivo para su fabricación, como es el uso de moldes de madera configurados mediante piezas desmontables.

Cuestión interesante que merece la pena ser estudiada en el futuro es la reutilización de material latericio. Sin duda las necrópolis son un ámbito muy adecuado para ello, dada la proliferación que se aprecia de este 
tipo de material constructivo en las tumbas tardías, que no en todos los casos habrían sido reutilizados. Asimismo, la decadencia arquitectónica que se produce en los periodos tardorromano y tardoantiguo habrían propiciado la necesidad y posibilidad de acudir a materiales de reempleo y, entre ellos, los ladrillos habrían sido un objetivo prioritario.

Quizás el aspecto más desconocido o menos estudiado y valorado en relación con el uso del material latericio sea el de la epigrafía. Es también un ámbito de trabajo en el que aún queda mucho por hacer y de gran interés desde el punto de vista de la producción. En esta primera aproximación al elenco de sigilla presentes tanto en Carteia como en Baelo, hemos podido constatar datos de cierta relevancia que alimentan el conocimiento del trabajo de las figlinae - percibido sobre todo por sus fabricaciones de vasos cerámicos- relativo a las producciones latericias. En este sentido, la posible interpretación de los sigilla como marcas de contabilidad parece confirmarse. Asimismo la presencia de dichos sigilla en la construcción de determinados edificios, como en el caso de las termas de Baelo, constituye un gran indicio a la hora de determinar su cronología con el apoyo de otros argumentos.

Por otro lado, la dualidad de sellos en ánforas y material constructivo no deja lugar a dudas de la fabricación de ambos en los mismos talleres. Dicha manufactura polivalente puede entenderse desde la consideración estacional de los procesos pesqueros —en el caso de las ciudades costeras que nos ocupan- $-y$, en consecuencia, de las necesidades también estacionales de fabricación de los contenedores. La presencia de dichos sígilla sobre ladrillos o tegulae de época republicana, como los de Carteia, nos indican que este material no era desconocido en las figlinae de la Betica en este periodo aunque su uso fuera aún muy concreto y específico.

\section{BIBLIOGRAFÍA}

Arévalo, A. y Bernal, D. 2007a: "Marcas epigráficas en material constructivo latericio de la factoría de salazones de Baelo Claudia (Provincia Baetica)", en M. Mayer i Olivé, G. Baratta y A. Guzmán Almagro (eds.), Acta XII Congressus Internationalis Epigraphiae Graecae et Latinae. Provinciae imperii romani inscriptionibus descriptae (Barcelona 3-8 septiembre 2002), pp. 73-80. Institut d'estudis catalans, Barcelona.

Arévalo, A. y Bernal, D. 2007b: Las cetariae de Baelo Claudia: avance de las investigaciones arqueológicas en el Barrio Meridional. Servicio de Publicaciones de la Universidad de Cádiz, Sevilla.

Arévalo, A., Blánquez, J. y Roldán, L. (en prensa): “El taller monetal de Carteia (San Roque, Cádiz): recientes testimonios arqueológicos”, $X V$
Congreso Nacional de Numismática. Patrimonio numismático y museos (Madrid 28-30 octubre 2014).

Bendala, M. y Roldán, L. 1997: "El cambio tecnológico en la arquitectura hispanorromana: perduración, novedades y peculiaridades”, en P. Bueno Ramírez y R. de Balbín Behrmann (coors.), II Congreso de Arqueología Peninsular (Zamora 24-27 septiembre 1996), vol. 4, pp. 103-116. Fundación Rei Alfonso Henriques, Madrid.

Bernal, D. 2011: "Las necrópolis tardoantiguas de Carteia. Nuevos documentos para su análisis”, en L. Roldán y J. Blánquez (eds.), Carteia III. Memorial, pp. 145-160. Universidad Autónoma de Madrid. Madrid.

Bernal, D., Arévalo, A., Muño, A., Expósito, J. A., Díaz, J. J., Lagóstena, J., Vargas, J., Lara, M., Moreno, E., Sáez, A. M. y Bustamante, M. 2013: “Las termas y el Suburbium marítimo de Baelo Claudia: avance de un reciente descubrimiento", Onoba, 01, pp. 115-152.

Bernal, D., Bustamante, M., Díaz, J. J. y Raissouni, B. 2012: "Sellos latericios del castellum de Tamuda (Marruecos)", Boletín de la Secah, 4, pp. 14-16.

Bernal, D., García Vargas, E., Lavado, M. L., Díaz, J. J., Luaces, M. y Gethsemaní, L. 2014: "M. Petrucidius y los hornos romanos y canteras de extracción de arcilla de La Vereda (Burguillos, Sevilla)", Boletín ex oficina, 5, pp. 26-31.

Berni Millet, P. 2010: "Epigrafia sobre amphorae, tegulae, imbrex i dolia a l'àrea occidental del Camp de Tarragona", en D. Gorostidi Pi (aut.), Ager Tarraconensis 3. Les inscripcions romanes (IRAT). The Roman Inscriptions, pp. 153-226. Institut d'Estudis Catalans, Tarragona.

Blánquez, J., Roldán, L. y Jiménez, H. (en prensa): “La nueva muralla púnica de Carteia (San Roque, Cádiz). Investigaciones del Proyecto Carteia Fase II (2006-2013)", VIII Congresso Internazionale di Studi Fenici e Punici: Dal Mediterranea all'Atlantico: uomini e idee tra Oriente e Occidente (Carbonia, San 'Antioco (Cerdeña), 21 - 26 de octubre de 2013).

Böcking, W. 1978: Die Römer am Niederrhein: die Ausgrabungen in Xanten, Westfalen und Niedersachsen. Frankfurt.

Bouet, A. 1999: Les matériaux de construction en terre cuite dans les thermes de la Gaule Narbonnaise. Scripta Antiqua, 1, Bordeaux.

Bourgeois, A. y Del Amo, M. 1970: "La quatrième campagne de Fouilles à Belo-Bolonia (Province de Cadix) en 1969", Mélanges de la Casa de Velázquez, VI, 439-464.

Broughton, T. R. S. 1951: The magistrates of the Roman Republic. American Philological Association, New York.

Camporeale, S. 2015: "I laterizi della Mauretania Tingitana. Materiali per una tipologia » in E. Bukowiecki, R. Volpe, U. Wulf-Rheidt (a cura di), Il laterizio nei cantieri imperiali. Roma e il Mediterraneo (Atti del I workshop "Laterizio" - Roma, 27-28 novembre 2014), Archeologia dell'Architettura XX, 2015, 145-157.

Ceán Bermúdez, J. A. 1832: Sumario de las antigüedades romanas que hay en España, en especial las pertenecientes a Bellas Artes. Imprenta de D. Miguel de Burgos, Madrid.

Chic García, G. 2001: Datos para un estudio socieconómico de la Bética. Marcas de alfar sobre ánforas olearias. Editorial Gráficas Sol, Écija.

Da Silva, L. y Ferreira, R. 2002: "Marcas de oficina em tijolos romanos de Seilium", Conimbriga 41, pp. 257-267.

Del Hoyo, J. 2006: "Corpus Epigráfico", en L. Roldán, M. Bendala, J. Blánquez y S. Martínez (dirs.), Estudio histórico arqueológico de la Ciudad de Carteia (San Roque, Cádiz) 1994-1999, Monografías de Arqueología Andaluza. Colección Arqueología 24, CD. Madrid.

Díaz Rodríguez, J. J. 2011: "Los centros productores cerámicos en las dos orillas del Círculo del Estrecho en la Antigüedad. Análisis comparativo de sus trayectorias alfareras", en D. Bernal, B. Raissouni, M. Arcila, M. Youbi Idrisi, J. Ramos, M. Zouak, J. A. López Sánchez, M. Maatouk, A. El Khayari,B. El Moumni, M. Ghottes y A. Azzariohi (eds.), Arqueología y Turismo en el Círculo del Estrecho. Estrategias para la Puesta en Valor de los recursos patrimoniales del Norte de Marruecos, Colecciones de Monografias del Museo Arqueológico de Tetuán (III), pp. 545-587. Servicio de Publicaciones de la Universidad de Cádiz y Servicio de Publicaciones de la Diputación de Cádiz, Cádiz.

Domergue, C. 1973: Belo I. La stratigraphie. Publications de la Casa de Velazquez. Série "Archéologie" Fasc. I, Éditions E. de Boccard, Paris. 
Étienne, R. y Mayet, F. 1971: "Briques de Belo. Relations entre la Maurétanie tingitane et la bétique au Bas-Empire", Mélanges de la Casa de Velázquez, VII, pp. 59-74.

Étienne, R. y Mayet, F. 1994: “A propos de l'amphore Dressel 1C de Belo (Cadix)", Mélanges de la Casa de Velázquez, XXX, pp. 131-138.

Étienne, R., Fabre, G. y Lévèque, P. M. 1976: Fouilles de Conimbriga. II Epigraphie et esculpture. Paris.

Fernández Ochoa, C., Morillo, A. y Zarzalejos, M. 1999: "Material latericio en las termas romanas de Hispania", en M. Bendala, Ch. Rico y L. Roldán (eds.), El ladrillo y sus derivados en época romana. Monografías de Arquitectura Romana, 4, pp. 291-306. Universidad Autónoma de Madrid, Madrid.

Fincker, M. 1986: "Les briques claveaux: un matériau de construcción spécifique des thermes romains", Aquitania, 4, pp. 143-150.

Fincker, M. 2008: "Étude architectural du sanctuaire. Analyse structurelle et stylistique ey organisation des espaces", en S. Dardaine, M. Fincker, J. Lancha, J. y P. Sillières (auts.), Belo VIII. Le sanctuaire d'Isis, pp. 67-152. Casa de Velázquez, Madrid.

Furgus, J. 1907: "Les ruines de Bélon, province de Cadix (Espagna)", Annales de la Société Archéologique de Bruxelles, XXI, pp. 149-160.

Gómez Araujo, L. 2013: "Revisión interpretativa y cronológica de las termas de Baelo Claudia: nuevas propuestas", Antiquitas, 25, pp. 165-176.

González, J. 1989: “M. Petrucidius M. F. Legatus Pro Pr”, Athenaeum fasc. III-IV, pp. 517-523.

Gros, P. 1983: Architecture et société à Rome et en Italie centro-méridionale aux deux derniers siècles de la république, Collection Latomus 156. Bruxelles.

Lagóstena, L. y Bernal, D. 2004: “Alfares y procucciones cerámicas en la provincia de Cádiz. Ba-lance y perspectivas”, en D. Bernal y L. Lagóstena (eds.), Congreso Internacional Figlinae Baeticae. Talleres alfareros y producciones cerámicas en la Bética romana (ss. II a. C.-VII d. C.). B.A.R., I. S 1266, pp. 39-124. Oxford.

Lancaster, L. C. 2016: Innovative Vaulting in the Architecture of the Roman Empire 1st-4th Centuries CE, Cambridge University Press.

Lenoir, E. 1991: "Thermes romains de Maurétanie Tingitane”, en Y. Thébert (ed.), Les thermes romains Actes de la table ronde de Rome (11-12 novembre 1988), pp. 151-160. Collection de l'École française de Rome 142, Roma.

Liz Callejo, C. 1974: "Nuevos hallazgos arqueológicos en Villavieja de Muñó (Burgos)", Boletín de la Institución Fernán González 1er sem. Año 53, n. 182 , pp. 119-126.

Mar Medina, R. 2008: "La construcción pública en las ciudades hispanas. Los agentes de la construcción, in Arqueología de la construcción I. Los procesos constructivos en el mundo romano: Italia y las provincias occidentales", en S. Camporeale, H. Dessales, A. Pizzo (eds.), Arqueología de la construcción I. Los procesos constructivos en el mundo romano: Italia y provincias occidentales. Anejos de AEspA L, pp. 175-190. Mérida.

Mayet, F. 1971: "Chronique. La cinquième champagne de fouilles à Belo (province de Cadix) en 1970”, Melanges de la Casa de Velázquez, VII, pp. 405-410.

Ménanteau, L., Vanney, J. R. y Zazo, C. 1983: "Belo et son environnement (Detroit de Gibraltar). Etude physique dùn site antique", Belo II, Publications de la Casa de Velázquez. Serie Archeologie, Fasc. IV, pp. 125-138. París.

Mueden, R. 2008: “Aspectos económicos de la comarca de Tingis (Mauritania Tingitana)”, en J. González, P. Ruggeri, C. Vismara y R. Zucca (eds.), L'Africa Romana XVII, le ricchezze dell'Africa : risorse, produzioni, scambi : atti del XVII Convegno di studio, Atti del XVII convegno di studio (Sevilla, 14-17 dicembre 2006), pp. 417-424. Carocci.

Nielsen, L. 1990: Thermae et Balnea. Denmark.

Paris, P., Bonsor, G., Laumonier, A., Ricard, R. y Mergelina, C. 1926: Fuilles de Belo (Bolonia, Province de Cadix). París.

Peacock, D. P. S. 1977: "Bricks and tiles of the Classis Britannia: petrology and origin" Britannia, 8, pp. 235-248.

Peacock, D. P. S. 1982: Pottery in the Roman World: an Ethnoarchaeological Approach. Addison-Wesley Longman Limited, New York.
Pellicioni, M. T. 2010: "Punzioni e nominativi: spunti per un'ipotesi sul fenómeno della bollatura dai laterizi della Regio Octava Aemilia”, en G. Bottazzi y P. Bigi (eds.), La produzione laterizia nell'area appenninica della Regio Octava Aemilia, pp. 17-27. San Marino.

Ponsich, M. 1970: Recherches archéologiques à Tanger et sa région. CNRS, París.

Presedo, F., Muñíz, J., Santero, J. M. y Chaves, F. 1982: Carteia I, Excavaciones Arqueológicas en España 120. Madrid.

Presedo, F. J. y Caballos, A. 1988: "La ciudad de Carteia: estado de la cuestión y primeros resultados de la campaña de 1985", en G. Pereira Menaut (dir. congr.), Actas del Primer Congreso Peninsular de Historia Antigua, (Santiago de Compostela, 1-5 julio 1986), vol. II, pp. 509-519. Universidad de Santiago de Compostela.

Rico, C. 1993: "Índex de les marques epigràfiques sobre tegulae romanes de Catalunya i el País Valencià (antigia Tarraconensis)", Saguntum. Papeles del Laboratorio de Arqueología de Valencia, 28, pp. 197-215.

Rico, C. 1999: "Éleménts pour une approche socio-économique de la production de matériaux de construction en terre cuite dans les provinces hispaniques", en M. Bendala, Ch. Rico y L. Roldán (eds.), El ladrillo y sus derivados en la época romana, Monografías de Arquitectura Romana 4, pp. 25-44. Universidad Autónoma de Madrid, Madrid.

Rodá de Llanza, I. 2015: Un episodi dintre de les humanitats: l'epigrafia. Epigrafia "major" $i$ "menor": l'exemple del fa bricant de teules Herenni Optat. Reial Acadèmia de Bones Llletres de Barcelona, Tarragona.

Roldán, L. 1992: Técnicas constructivas romanas en Carteia (San Roque, Cádiz), Monografías de Arquitectura Romana 1. Universidad Autónoma de Madrid, Madrid.

Roldán, L. 1995: "Aspects constructifs des thermes romain de la Baetica”, en M. Khanoussi, P. Ruggeri y C. Vismara (coors.), Atti dell'XII Convegno di Studi sull'Africa romana (Cartagine, 15-18 dicembre 1994), pp. 789-821. Sassari.

Roldán, L. 1999: “Arquitectura pública en las ciudades de la Bética. El uso del opus testaceum”, en M. Bendala, C. Rico y L. Roldán (eds.), El ladrillo y sus derivados en la época romana. Monografías de Arquitectura Romana 4, pp. 179-204. Universidad Autónoma de Madrid, Madrid.

Roldán, L. 2008: "El material constructivo latericio en Hispania. Estado de la cuestión, in Cerámicas hispanorromanas. Un estado de la cuestión”, en D. Bernal y A. Ribera i Lacomba (coors.), Cerámicas hispanorromanas. Un estado de la cuestión, pp. 749-773. Servicio de Publicaciones de la Universidad de Cádiz, Cádiz.

Roldán, L. y Blánquez, J. 2011: "Las excavaciones en Carteia en la década de los años 50: Julio Martínez Santa-Olalla (1953-1961)”, en L. Roldán y J. Blánquez (eds.), Carteia III. Memorial, pp. 121-144. Universidad Autónoma de Madrid, Madrid.

Roldán, L. y Blánquez, J. 2012: “Julio Martínez Santa-Olalla. Una historia arqueológica por escribir”, en L. Roldán y J. Blánquez (eds.), Julio Martínez Santa-Olalla y el descubrimiento arqueológico de Carteia (1953-1961), pp. 95-112. Universidad Autónoma de Madrid y Trébede Ediciones, Madrid.

Roldán, L., Bendala, M., Blánquez, J. y Martínez, S. (dirs.), 2006: Estudio histórico-arqueológico de la Ciudad de Carteia (San Roque, Cádiz) 1994 1999 (2 vol. y CD), Monografías de Arqueología Andaluza. Colección Arqueología 24, Universidad Autónoma de Madrid y Dirección General de Cultura de la Junta de Andalucía, Madrid.

Roldán, L., Blánquez, J., Bernal, D., Prados, F. y Díaz, J. J. 2006: “El barrio alfarero de Carteia. Intervenciones de urgencia en Villa Victoria (San Roque, Cádiz) en el año 2003", Anuario Arqueológico de Andalucía 2003. III Actividades de Urgencia vol. 1, pp. 151-164.

Roldán Gómez, L. y Bustamante Álvarez, M. 2015: “The production, dispersion and use of bricks in Hispania", in E. Bukowiecki, R. Volpe, U. Wulf-Rheidt (a cura di), Il laterizio nei cantieri imperiali. Roma e il Mediterraneo (Atti del I workshop "Laterizio" - Roma, 27-28 novembre 2014), Archeologia dell'Architettura XX, pp. 135-144.

Rouillard, P., Remesal, J. y Sillières, P. 1975: "Neuvième campagne de fouilles de la Casa de Velázquez à Baelo 1974", Mélanges de la Casa de Velázquez 11, pp. 509-534.

Shepherd, E. 2007: Considerazioni sulla tipologia e diffusione dei laterizi da copertura nell'Italia tardo-repubblicana, BCAR 108. Rome. 
Sillières, P., 1995: Baelo Claudia une cité romaine de Bétique, Madrid.

Sillières, P. 1997: Baelo Claudia. Una ciudad romana de la Bética. Casa de Velázquez, Madrid.

Spitzlberger, G. 1968: "Die römischen Ziegelstempel im nördlichen Teil der Provinz Rätien”, Saalburg Jahrbuch, 25, pp. 65-183.

Steinby, M. 1982: "I senatori e l'industria laterizia urbana" en: Caldelli, M. L.; Gregori, G. L. Epigrafie e ordine senatorio I, Tituli, Edizioni Quasar, Roma, pp. 227-237

Steinby, M. 1993: 'L'organizzazione produttiva dei laterizi: un modello interpretativo per l'instrumentum in genere?", en W. V. Harris (ed.), The inscribed economy: production and distribution in the Roman Empire in the light of instrumentum domesticum, Ann Arbor: Journal of Roman Archaeology, pp. 139-143.

Thouvenot, R. 1954: "Les manufactures impériales au Maroc Romain", $P u$ blications du Service des Antiques du Maroc 10, pp. 213-216.
Torrecilla, A., Sánchez, S., Gómez, E. y Ochoa, A. 2002: "Los materiales constructivos (tégulas, imbrices y ladrillos)", en D. Bernal y L. Lorenzo (eds.), Excavaciones Arqueológicas en la Villa romana del Puente Grande (Los Altos del Ringo Rango, Los Barrios, Cádiz), pp. 255-270. Cádiz.

Veiga Silva Pereira, M. L. 1974-1977: "Marcas de oleiros algarvios do período romano", O Arqueólogo portugués série III, vols. VII-IX, pp. 243-268.

Villaverde, N. 2001: Tingitana en la Antigüedad Tardia (siglos III-VII). Real Academia de la Historia, Madrid.

Wilkes, J. 1979: "Importation and manufacture of stamped bricks and tiles in the roman province of Dalmatia", en A. McWhirr (ed.), Roman Brick and Tile. Studies in Manufacture, Distribution and Use in the Western Empire, BAR International Series 68, pp. 65-72. Oxford. 